\title{
LACTOSE-FERMENTING BACTERIA IN FAECES.
}

\author{
By ALFRED MacCONKEY, M.B., D.P.H. \\ (Senior Assistant Bacteriologist, Serum Department, Lister Institute \\ of Preventive Medicine.)
}

THE following experiments were begun with the object of ascertaining the distribution in nature of certain lactose-fermenting organisms which are by some grouped under the name Bacillus coli, but by others are regarded as belonging to a different class of organisms; a difference of opinion which is most probably the principal factor in causing the value of $B$. coli as an index of pollution to be such a vexed question among bacteriologists. The investigation, however, resolved itself into a search for the $B$. lactis aerogenes principally, and secondarily for the other lactose fermenters. Incidentally certain other points are referred to which it was thought might prove of interest though not actually pertaining to the subject of the paper.

For facility of reference the paper has been divided into sections :-

Section 1. Media-Action of potassium iodide-Methods.

Section 2. Characters of certain lactose-fermenting bacilli; Voges and Proskauer's reaction.

Section 3. Effect of environment upon biological characteristics.

Section 4. Question of preliminary incubation in a liquid medium.

Section 5. Experiments :-

(a) Examination of human faeces.

(b) Examination of animal faeces.

(c) Examination of milk.

(d) Examination of animal faeces when the animal was fed on a partially sterilised diet.

(e) Examination on successive occasions of a mixture of tapwater and human faeces. 
Section 6. The fermentation of starch and inulin.

Section 7. Voges and Proskauer's reaction as a test for the presence of $B$. lactis aerogenes and B. cloacae.

\section{Section I.}

A. Media.

In these experiments the ordinary nutrient media were used as well as bile-salt media ${ }^{1}$. The basis of the latter consisted of a stock solution composed of :-
Sodium taurocholate (commercial),
0.5 gms.
Peptone (Witte),
$2 \cdot 0$ gms.
Distilled water,
100 c.c.

For liquid media there is added to this stock solution $0.5 \%$ of a $1 \%$ solution of neutral-red and $0.5 \%$ of glucose, or $1 \%$ of the other carbohydrates or alcohols, as the case may be, and the medium is distributed into Durham's fermentation tubes ${ }^{2}$ and sterilised in the steamer for 10 minutes on each of two days, great care being taken not to overheat the medium. If it be thought advisable white of egg may be used to clear the medium.

Bile-salt agar is made by dissolving $155 \%-2 \%$ agar in the stock solution. This is best done in the autoclave. The medium is cleared with white of egg and filtered. After filtration the same amount of neutral-red is added as in the case of the liquid media. Some workers add alkali to this agar but I much prefer it without, as the increased alkalinity delays the appearance of the acid reaction in the case of some organisms. Neutral-red (suggested in this connection by Grünbaum and Hume, 1902) is used as an indicator in preference to litmus because the medium is light-coloured and the differentiation much sharper. The solution of the dye should be freshly prepared, as with old solutions the result is often not so satisfactory. The addition of glycerine is to be avoided, as it seems to interfere with the sharp differentiation usually obtained. The various carbohydrates and alcohols are added, in the same proportions as for liquid media, any time after filtration, the particular kind or kinds to be added depending upon the purpose for which the agar is to be used. It is convenient to follow the plan of Drigalski and Conradi, and distribute the agar into small flasks con-

1 Thompson Yates Laboratories Reports, 1900-1901.

${ }^{2}$ Brit. Med. Journ., Vol. I. p. 138. 
taining about 80 c.c., which is enough for three Petri dishes of the ordinary size. A consideration of the fermentation-reactions of the various organisms shows that by the use of certain substances, either alone or in combination, we can separate organisms by means of colour reactions. Thus, if lactose alone be added to the agar, only the lactosefractors will produce acid and show pink colonies; if dulcite alone only the dulcite fermenters; if sorbite alone only the sorbite fermenters, and so on. This is the idea underlying all such differential media as Wurtz litmus-lactose agar, or the litmus-lactose-nutrose agar of Drigalski and Conradi. If this principle be extended by combining two or more of these carbohydrates or alcohols in the agar, we can obtain a larger number of organisms giving coloured colonies, and can thus if desirable exclude them, leaving only the colourless colonies for examination. Thus by using lactose and dulcite we include Gaertner's bacillus among the acid producers. The addition of sorbite gives an agar upon which the Bacillus typhosus will produce coloured colonies. Cane-sugar will exclude B. proteus vulgaris, and mannite one of the varieties of B.dysenteriae, that is, of course, on the presumption that only colourless colonies are to be taken for further investigation. It must, however, be clearly understood that it is not suggested that exactly similar results will be obtained always when working with the organisms in unknown mixtures, as in such cases we must take into account the possibility of the presence of transition forms between one group and another, and of bacilli which may have been weakened as regards their fermentative powers by unfavourable environment. Still, making allowance for both these possibilities, we can certainly lighten our labour in searching for, say, $B$. dysenteriae by excluding all those organisms in the mixture which at the time of experiment are capable of fermenting lactose, dulcite, sorbite, and cane-sugar, and if desired mannite also.

On bile-salt neutral-red lactose agar the surface colonies of B. cloacae, after about 20 hours in the incubator at $37^{\circ} \mathrm{C}$., are usually found raised and opalescent, and some may have a red centre. With lapse of time they tend to run together into masses of mucoid-looking material with spots of deep red in them. The centres of all those colonies which remain discrete become red inside 48 hours. In 3 days the red colour may have entirely disappeared, being succeeded by a brownish-yellow colour. On a bile-salt neutral-red agar containing lactose 1\% and sorbite $0.5 \%$ the $B$. enteritidis (Gaertner), after 24 hours' incubation at $37^{\circ} \mathrm{C}$, gives a pink growth, which usually changes to brownish-yellow during the succeeding 24 hours. 
With the object of stimulating the growth of B. typhosus bile-salt agar has been modified by the addition in varying percentages of the following substances:-Urea, asparagin, Liebig's extract, nutrose, somatose, roborat, plasmon, Nährstoff Heyden, $\mathrm{CaCl}_{2}, \mathrm{Na}_{2} \mathrm{HPO}_{4}, \mathrm{KNO}_{3}, \mathrm{KI}$, serum, and a solution of alkaline-haematin. This latter solution was made by dissolving 7 grammes of haemoglobin in 10 c.c. of $\frac{n}{1} \mathrm{NaHO}$, and diluting to 100 c.c. with distilled water. $\mathrm{Na}_{2} \mathrm{HPO}_{4}$ seemed distinctly deleterious. Of the others only 5 had any apparent stimulating effect. These were :

\begin{tabular}{|c|c|}
\hline $\mathrm{CaCl}_{2}$ in the proportion of & 0.034 per cent. (cf. Gabritschewsky), \\
\hline Serum & $1 \cdot 0$ \\
\hline Alkali-haematin solution & $1 \cdot 0$ \\
\hline $\mathrm{KNO}_{3}$ & 0.5 \\
\hline KI & 0.5 \\
\hline
\end{tabular}

\section{B. Action of Potassium Iodide.}

With regard to potassium iodide Elsner (1896) was the first to suggest its use in culture media. He states that his acid potato gelatin with KI $1 \%$ inhibits most organisms except the coli and typhosus groups, and that even $B$. proteus and B. mesentericus do not grow well upon it. L. Grimbert (1896) disputes this statement and says that by adding non-sterilised water to tubes of Elsner's medium he obtained growth of non-pathogenic liquefying bacteria. A. Moore (1902) when using Elsner's medium found that the development of liquefying organisms frequently spoilt his plates, and to avoid this he made use of a potassium iodide potato agar, which, however, was alkaline and not acid as recommended by Elsner. Fermi (1898), tested the effect of a large number of chemical substances upon some 80 odd varieties of organisms. His stock culture medium was a neutral agar. He found B. typhosus would not grow in contact with more than $0.3 \%$ potassium iodide ; while $B$. coli could not withstand more than $0.75 \%$ of the same salt.

My experiments lead me to conclude that on bile-salt lactose agar with the addition of KI $0.5 \%-1 \%$ the B. typhosus gives larger surface colonies than on the same agar without $\mathrm{KI}^{1}$. It must be remembered that the medium is alkaline to litmus and not acid, like Elsner's gelatin.

1 The growth of $B$. pestis on bile-salt agar is also stimulated by the addition of $0.5 \% \mathrm{KI}$. 
A few experiments showing the effect of $\mathrm{KI}$ are given below:-

$B$. proteus vulgaris, B. cloacae, and B. typhosus were all grown in tubes of bile-salt mannite broth containing $0.5 \% \mathrm{KI}$ and were compared with the same organisms grown in control tubes without KI. No difference in the amount of growth as evidenced by turbidity of fluid and amount of acid or gas production could be made out.

B. typhosus was inoculated into two fermentation tubes of nutrient broth containing $2 \%$ glucose, and to one tube $1 \% \mathrm{KI}$ was added and to the other $2 \%$ KI. After 24 hours' incubation at $37^{\circ} \mathrm{C}$. there was no apparent difference in the amount of growth in the bulbs, but the fluid in the closed arm of the $2 \% \mathrm{KI}$ tube was much clearer than that in the other tube. After 48 hours' incubation no difference could be made out between the two tubes.

Potassium iodide $0.5 \%$ was added to broth containing $2 \%$ glucose, and the medium was distributed into three fermentation tubes which were inoculated respectively with $B$. coli communis (Escherich), B. capsulatus (Pfeiffer), and B. cloacae (Jordan). After 3 days' incubation at $37^{\circ} \mathrm{C}$., the results were :-

B. coli communis (Escherich)

B. capsulatus (Pfeiffer)

B. cloacae (Jordan)

$\begin{gathered}\text { Amount of gas } \\ \% \text { of closed arm }\end{gathered}$
30
90
100

$$
\begin{aligned}
& \frac{\mathrm{H}}{\mathrm{CO}_{2}} \quad \text { Voges and Proskauer's reaction ' } \\
& \frac{3}{2}+\text { - } \\
& \frac{1}{2} \text { trace after } 24 \text { hours' standing. } \\
& + \text { after } 48 \text { hours' standing. }
\end{aligned}
$$

1 See below, p. 350, hereinafter referred to as V. and P. reaction in the tables.

Nutrient broth containing $2 \%$ glucose was filled into fermentation tubes, and $1 \% \mathrm{KI}$ was added. The tubes were inoculated and incubated at $37^{\circ} \mathrm{C}$. for 48 hours, when the results were :-

B. coli communis (Escherich)

B. lactis aerogenes (Escherich)

B. cloacae (Jordan)

B. proteus vulgaris

Amount of gas
$\%$ of closed arm
45
80
100
10

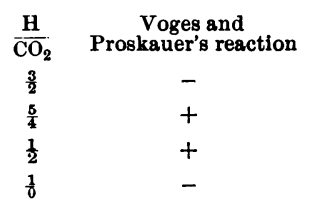

A broth composed of glucose $1 \%$, sod. taurochol. $0.5 \%$, peptone $2.0 \%$, aq. dist. 100 c.c. $\pm 0.5 \% \mathrm{KI}$ was used in a similar way. After 48 hours' incubation at $37^{\circ} \mathrm{C}$., the results were :- 
B. lactis aerogenes (Escherich)

B. capsulatus (Pfeiffer)

1T. W. F. 46

B. cloacae (Jordan)

B. coli communis (Escherich)

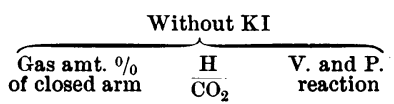

$\begin{array}{lll}40 & \frac{1}{1} & + \\ 60 & \frac{2}{3} & + \\ 40 & \frac{1}{1} & + \\ 70 & \frac{1}{2} & + \\ 25 & \frac{2}{1} & -\end{array}$

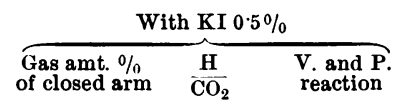

70

60

70

70

40

$\begin{array}{ll}\frac{2}{3} & + \\ \frac{1}{2} & + \\ \frac{2}{5} & + \\ \frac{2}{5} & + \\ \frac{2}{1} & -\end{array}$

1 This organism was isolated from faeces and will be referred to later in another experiment.

Just previously the same batch of broth had given :-

$\begin{array}{lllllll}B . \text { lactis aerogenes } & 45 & \frac{1}{1} & + & 33 & \frac{2}{1} & + \\ \text { B. cloacae } & 20 & 1 & + & 25 & 1\end{array}$

The results obtained with a similar broth but containing lactose instead of glucose were:-
B. lactis aerogenes (Escherich)
B. capsulatus (Pfeiffer)
B. coli communis (Escherich)
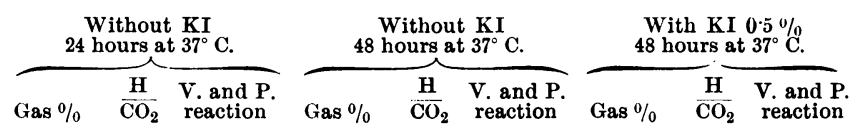

In the case of $B$. cloacae the growth in the bulb of the fermentation tube was good, but in the closed arm it was scanty.

In another experiment neutral nutrient bouillon was used instead of $2 \%$ peptone water to make a bile-salt-potassium-iodide-lactose broth. After 48 hours at $37^{\circ} \mathrm{C}$.,

B. capsulatus gave $10 \%$ of gas with a ratio of $\frac{5}{3}$ and no V. and P. reaction.

B. lactis aerogenes , $90 \quad, \quad, \quad, \quad, \quad \frac{4}{8}$ and a marked V. and P. reaction.

B. cloacae , , $7 \quad, \quad, \quad, \quad \frac{1}{0}$ and no V. and P. reaction.

B. colicommunis , , $25 \quad,, \quad, \quad, \quad \frac{4}{1} \quad, \quad, \quad, \quad, \quad$,

Another tube of B. cloacae after 7 days' incubation showed :-

$$
45 \% \frac{\mathrm{H}}{\mathrm{CO}_{2}}=\frac{5}{3} \text { V. and } \mathrm{P} \text {. reaction marked. }
$$

A broth of similar composition containing $1 \%$ of cane-sugar as the carbohydrate, instead of glucose or lactose, yielded, after 48 hours' incubation at $37^{\circ} \mathrm{C}$., the following results :- 
B. cloacae (Jordan)

B. capsulatus (Pfeiffer)

$B$. lactis aerogenes (Escherich)

B. coli communis (Escherich)

$B$. acidi lactici (Hüppe)

B. pneumoniae (Friedländer)

B. neapolitanus (Emmerich)

$B$. cloacae, inoculated from one above

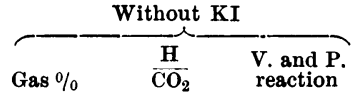

100

$\frac{1}{2}$

35

30

$\frac{1}{1}$
$\frac{1}{1}$

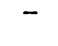

One bubble

One

bubble

75

and a third trial :-

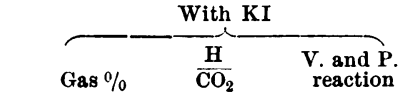

about 5 Tube broken before KHO added.

B. cloacae,

24 hours
48 hours
48 hours
3 days
72 hours
4 days
5 days
6 days

20

$\begin{array}{cccc}\ldots & \ldots & \ldots & 7 \\ 70 & & & \\ 90 & \frac{2}{3} & + & \\ \ldots & \ldots & \ldots & 14 \\ \ldots & \ldots & \ldots & 25 \\ \ldots & \ldots & \ldots & 50 \\ \ldots & \ldots & \ldots & 50\end{array}$

7

14

25

$50 \quad \frac{1}{2}+$

As Drigalski and Conradi recommend Krystall-Violett as an inhibitor of air organisms it was thought that this dye might on occasion be with advantage added to the broth. A few trials made it evident that this could be done without interfering either with the gas reaction or the production of Voges and Proskauer's reaction.

Taking these results all together it may be said :-

(1) that the addition of KI to bile-salt media may tend to delay the anaerobic growth while not interfering with multiplication aerobically; and

(2) that Voges and Proskauer's reaction is more constant than the "gas-reaction" of Theobald Smith as the former appeared in some cases when the latter was not characteristic.

\section{Methods.}

The method adopted was to emulsify a portion of the sample in a tube of bile-salt broth and to place this tube at $37^{\circ} \mathrm{C}$., for, usually, 18-24 hours, but occasionally 48 hours were allowed to elapse before 
plates were made. Gelatine plates were poured in the usual way, but agar plates were made after the manner of Drigalski and Conradi, i.e., the melted agar was poured into the plates, allowed to solidify and dried in the warm incubator for an hour or so. A loopful of the broth culture was put on the surface of one of the plates and rubbed over it with a bent glass rod, the same rod (without recharging) being used to inoculate a second and third plate. The plates were incubated at $37^{\circ} \mathrm{C}$, for $24-48$ hours. Ten colonies were, as a rule, taken from each set of plates and worked through the following media:-nutrient broth, nutrient agar, nutrient gelatine, litmus-milk, and bile-salt broths containing respectively glucose, lactose, mannite, cane-sugar, and dulcite. The cultures were also tested as regards their behaviour towards Gram's method of staining. At first potato was also used and media containing glycerine, starch.and inulin, but it was soon found that these media had no great value in these experiments and so their use was discontinued.

\section{Section II.}

\section{Characters of certain Lactose-fermenting Bacilli.}

As in later sections we shall be concerned with lactose-fermenting bacilli it is necessary that at the outset we should have a clear idea of the biological characters of some of the best known of these organisms, so that a comparison can be made between them and those isolated during the experiments. For this purpose I have collected the descriptions given by certain authors of the following bacilli :-

B. coli, B. acidi lactici (Hüppe), B. pneumoniae (Friedländer), B. lactis aerogenes (Escherich), and B. cloacae (Jordan).

Of these we have most knowledge concerning the $B$. coli as it has been the most carefully studied by a large number of workers. The principal characters ascribed to this organism have been gathered together in a table for ease of comparison and any special points are mentioned afterwards. The other organisms do not lend themselves to tabular description and so merely a statement has been given of the opinions expressed concerning them by the various authors mentioned.

Theobald Smith (1895) lays stress upon the amount of gas produced and upon the ratio of $\mathrm{H}$ to $\mathrm{CO}_{2}$ as of value in separating $B$. coli from the $B$. lactis aerogenes and $B$. cloacae. In dextrose broth $B$. coli produces sufficient gas to fill half of the closed arm of the fermentation 
A. MacConkey

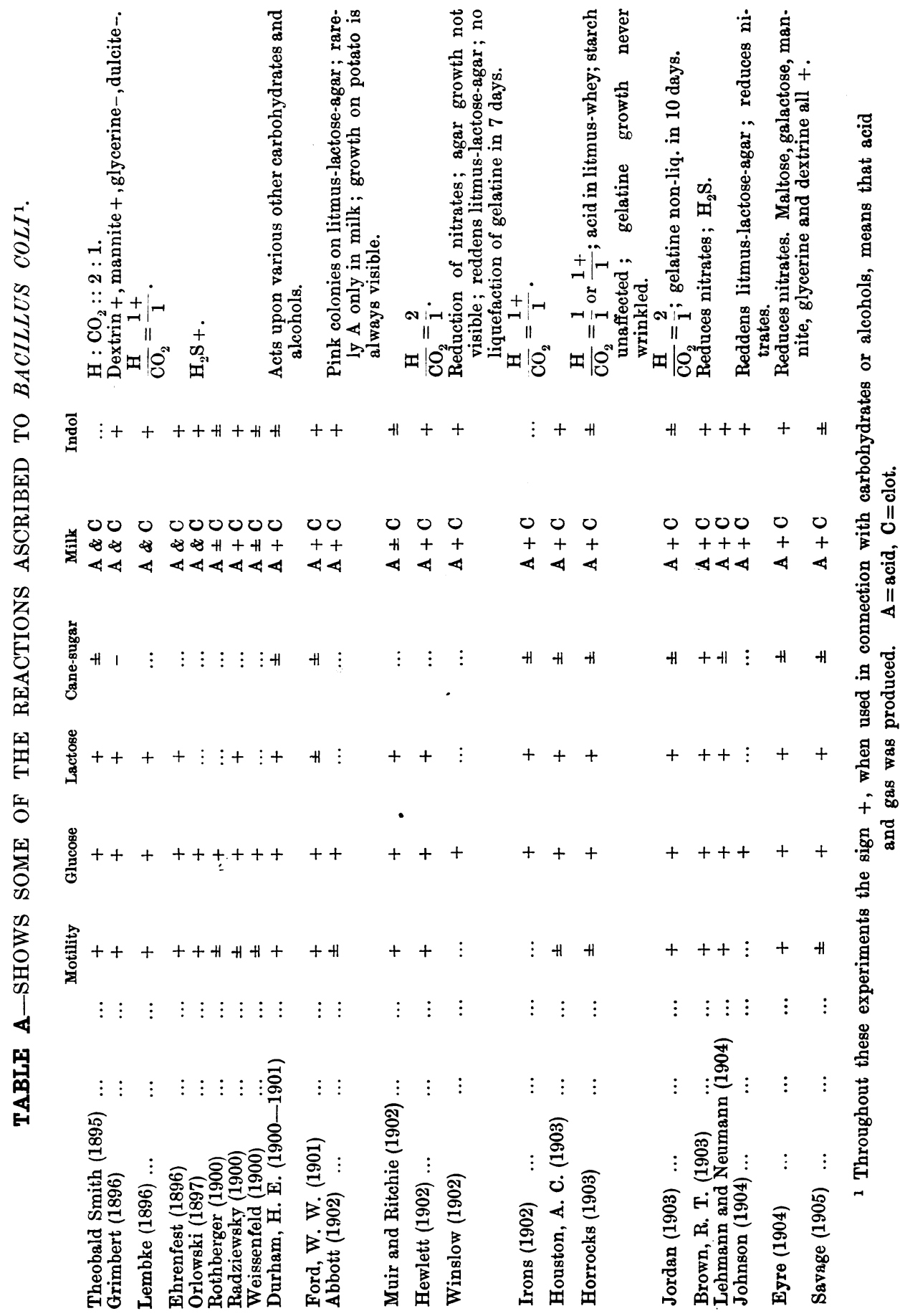


tube, the reaction of the medium is very acid, and the ratio of $\mathrm{H}$ to $\mathrm{CO}_{2}$ is as 2 to 1 . The acidity of 100 c.c. of bouillon $=5$ c.c. of $\frac{n}{1}$ alkali, the indicator being phenol-phthalein.

Grimbert (1896) considers the property of fermenting cane-sugar is not usual among the coli group.

Grimbert and Legros (1900) distinguish the coli group from the Friedländer group by

(1) its motility,

(2) the absence of capsules in the blood of inoculated animals,

(3) the production of indol in solutions of peptone.

Rothberger (1900) thinks that the motility of this organism varies very much; the same strain being motile at one time and apparently non-motile at another. The stock bacillus of the laboratory in which he worked was a motile bacillus giving the usual growths on agar and gelatine, general turbidity in broth, gas in sugar media, feeble indol, and no clot in milk in 10 days.

Radziewsky (1900) isolated 64 coli from faeces by means of gelatine plates, from which he picked off only the typical "vine-leaf" colonies. The resulting cultures were plated and re-plated to ensure pure growths. He found that some of these pure cultures gave, when planted, a mixture of typical "vine-leaf" colonies and of colonies which were round, raised, and with a regular unnotched edge.

Durham (1900-1901) has suggested that because of its greater relative frequency the name $B$. coli communior should be given to that form of $B$. coli which attacks cane-sugar, and that the B. coli communis (Escherich) which does not ferment cane-sugar should be termed the B. coli communis verus. He mentions that dextrose, laevulose, mannose, arabinose, galactose, and maltose, give acid or acid and gas with races which are able to ferment dextrose. Mannite and dextrin also react like dextrose in that those bacilli which give acid or gas with one of the former will do so with the latter.

W. W. Ford (1901) also considers that the most common B. coli is that which possesses the power of breaking up dextrose, lactose, and cane-sugar; a second variety splits up dextrose and lactose, but not cane-sugar; and a third acts on dextrose only.

Abbott (1902) thinks that the B. neapolitanus of Emmerich is the same organism as the B. coli communis of Escherich.

Hewlett (1902) states that the B. coli communis has been described under the names B. cavicida (Brieger), and B. neapolitanus (Emmerich). 
Horrocks (1902) describes a B. sulcatus gasoformans, a small, slightly motile, Gram-negative bacillus which gives growths like $B$. coli except that the surface of the gelatine growth becomes wrinkled in about five days. The gas-ratio in dextrose is about 2 to 1 . The amount of acid produced in litmus-whey after 7 days at $37^{\circ} \mathrm{C} .=20$ per cent. $\frac{n}{10}$ alkali.

Orlowski (1897) is of opinion that the $B$. coli is a very variable organism. He maintains,

(1) that there are many varieties in nature;

(2) that in favourable circumstances one kind may pass over into another;

(3) that such favouring conditions may be found in the animal body, as when he injected one strain he not infrequently found another in the blood and organs, while from the intestinal contents only typical B. coli was isolated ${ }^{1}$.

All these authors are agreed that $B$. coli is usually a short bacillus with rounded ends; that it does not retain the dye when stained by Gram's method; that it is a non-sporing facultative anaerobe; that the growth on agar is a greyish-white layer; that the typical surface colony on

1 I trust I may be pardoned for making a slight digression here to point out that such reasoning if applied to the following cases would lead to error.

From the heart-blood of a guinea-pig which had been inoculated with a pure culture of the $B$. malle $i$ isolated an actively motile, short rod, Gram-negative, giving ordinary grey-white growths on agar and gelatine without liquefying the latter, general turbidity in broth, no clotting in milk but preliminary slight acidity followed by marked alkalinity, and fermenting glucose, mannite, dulcite, and sorbite with the production of acid and gas, but having no effect on lactose or cane-sugar.

On another occasion two Roux bottles of nutrient agar were inoculated with a pure culture of $B$. typhosus of which the M.L.I. (guinea-pig 250 ) was $0 \cdot 2$ c.c. of a 24 hour broth culture given intraperitoneally. After 24 hours' incubation at $37^{\circ} \mathrm{C}$., the growth was swept off the surface of the agar and emulsified in 3 c.c. of $0.85 \% \mathrm{NaCl}$ solution. Onehalf of this emulsion (i.e. 1 Roux bottle $=15-20$ agar tubes) was injected subcutaneously into a guinea-pig weighing about 250 grammes. The animal died on the fourth day and from the heart-blood was isolated in pure culture a bacillus exactly like the one described above.

A similar organism appeared to be the cause of a small epidemic which broke out amongst our stock of experimental animals. The post-mortem naked-eye appearances were those of pseudo-tuberculosis rodentium. From four stock animals examined the bacillus referred to in the two previous paragraphs was isolated in pure culture from the liver.

This suggests that organisms which morphologically and culturally are indistinguishable from the $B$. enteritidis (Gaertner) may be much more widely distributed in nature than is at present recognised. It also emphasises the importance, especially in the examination of food-stuffs, of keeping animals under observation for some time previous to experiment so as to ensure that only healthy animals are used. 
gelatine is a "vine leaf," thin, filmy, translucent expansion; that gelatine is never liquefied; and that glucose is always fermented with the production of acid and gas. They differ, however, with regard to the fermentation of other carbohydrates and more particularly concerning cane-sugar. This is most probably due to the fact that organisms which give distinctly different fermentative reactions have been classed together as B. coli communis. But an organism can be termed B. coli communis (Escherich) only when it gives the constant reactions given by the original organism described by Escherich. Through the kindness of Dr H. E. Durham, who gave me a sub-culture of the original microbe, I have been able to study this bacillus closely. During the years I have had it in my possession it has varied somewhat in its morphology and in its growth on agar and gelatine, but its growth in milk and its fermentation reactions have remained constant. I, therefore, cannot agree that the $B$. neapolitanus of Emmerich is identical with the $B$. coli communis of Escherich.

It may be as well to mention here that the $B$. lactis aerogenes that I have worked with is also a sub-culture of the original strain obtained through Dr Durham.

\section{B. acidi lactici (Hüppe).}

Hewlett (1902) states that it is a non-liquefying, Gram-negative bacillus which produces growths something like those of coli but the film on gelatine is much denser.

Kruse (1903) considers the B. acidi lactici (Hüppe) to be identical with the $B$. lactis aerogenes (Escherich).

Prescott (1903) isolated "lactic acid bacteria" from various cereals and meals and from waters which were apparently free from all suspicion of faecal contamination and compared them with 23 varieties of $B$. coli which had been isolated from faeces or sewage. Of 64 cultures 44 gave the same cultural reactions, and of these 25 were lactic acid bacteria and 19 were coli. Morphologically there was no difference and all produced the same amount of acid when tested under the same conditions.

Lehmann and Neumann (1904) describe this organism as a short oval, non-motile rod, which is Gran-negative, and does not liquefy gelatine. The growth on agar resembles that of $B$. coli but is viscid. It produces general turbidity in broth, indol in peptone solutions, clotting in milk, and acid and gas in glucose and lactose. They consider it to be identical with $B$. lactis aerogenes (Escherich), and that the 
B. cavicida (Brieger) and B. neapolitanus (Emmerich) are most closely related to it.

\section{B. lactis aerogenes (Escherich).}

Theobald Smith (1895) says that one variety of B. lactis aerogenes, isolated from water, is only differentiated from true $B$. coli by its want of motility. The true B. lactis aerogenes is differentiated by the amount of gas produced and by the composition of the gas: gas-production in glucose $=80 \%-100 \%, \frac{\mathrm{H}}{\mathrm{CO}_{2}}=\frac{1}{1}$ or $\frac{1}{1+}$.

Strong (1899) discussing capsulated bacilli divides them into two groups :

Group I. B. pneumoniae (Friedländer), B. Wright and Mallory, B. ozaenae, B. sputigenes crassus, and B. rhinoscleromatis. Gas production: cane-sugar $50 \%$, glucose $30 \%$, lactose $30 \%$ or maybe none. No clotting of milk.

Group II. B. aerogenes, B. capsulatus (Pfeiffer), B. capsulatus (Kruse). Gas production in all sugars about the same but most in canesugar. Milk is clotted.

J. Rothberger (1900) describes it as a non-motile bacillus which does not form indol. It produces general turbidity in broth, acid and clot in milk, and ferments glucose with production of acid and gas. On agar the growth is whitish and slimy, or soft and whitish with a smooth margin. The surface growth of a stab gelatine culture is greybrown, dry and slightly irregular.

Grimbert and Legros (1900) think that B. lactis aerogenes (Escherich), and B. pneumoniae (Friedländer) are the same organism because :

(1) they are non-motile;

(2) they have capsules in the blood of inoculated animals;

(3) they do not liquefy gelatine;

(4) they do not produce indol ;

(5) they ferment carbohydrates and alcohols, even though the same substances are not always attacked by both bacilli.

B. pneumoniae (Friedländer) ferments dulcite, whereas the B. lactis aerogenes does not.

Durham (1900 - 1901) places B. lactis aerogenes among the polysaccharide fractors, and states that it ferments dextrose, lactose, canesugar, and may, or may not, ferment starch and inulin. He notes that all the bacilli of this group which were tested by him gave the Voges 
and Proskauer's "Kalilauge-roth-reaktion," while the bacilli of the other groups mentioned in his paper failed to do so.

Ford (1901) considers there are three forms of this organism; the most common form fermenting glucose, lactose, and cane-sugar; the second form acting on dextrose and lactose, but not on cane-sugar; and the third splitting dextrose only.

Hewlett (1902) gives the fermentation of starch and inulin as characteristics of this bacillus.

Muir and Ritchie (1902) think that this bacterium is either a variety of $B$. coli or a closely related organism. It is distinguished by its more abundant gas-production, and by its growth on gelatine and agar being thicker and whiter than that of coli.

Jordan (1903) describes it as a non-motile, non-liquefying bacillus which may not curdle milk until the 9 th or 10th day. The gelatine colonies differ from those of coli in that they are less spreading, more convex and fleshy, with smooth, well-defined margins. Indol is usually produced and dextrose; lactose and cane-sugar fermented though the latter may not be acted upon.

Horrocks (1903) characterises it as a small non-motile, Gram-negative bacillus producing on agar a greyish-white tenacious growth. The gelatine colonies are thicker, and more opaque than those of coli. On potato the growth is coloured and gas-bubbles may appear on the surface. Milk is acidified and clotted. Indol is formed in peptone water. Glucose, lactose, cane-sugar and starch are fermented with the production of acid and gas. He also says, "Judging this organism by its power of fermenting starch, I cannot say it is frequently found in sewage polluted waters."

Paul Clairmont (1902) states that it is non-motile, gives the usual growth on agar and gelatine, does not produce indol, acidifies and clots milk, and ferments glucose, lactose, and cane-sugar.

Lehmann and Neumann (1904) consider the $B$. lactis aerogenes to be identical with the $B$. acidi lactici (Hüppe). It does not form indol, and is only differentiated from $B$. coli by its want of motility.

Taking all these opinions together the B. lactis aerogenes (Escherich) might be described as a non-motile, Gram-negative, non-liquefying bacillus, a facultative anaerobe, producing acid and clotting in milk, fermenting glucose, lactose, and cane-sugar and maybe also starch and inulin, and giving Voges and Proskauer's "Kalilauge-roth-reaktion" (see foot of p. 349). 


\section{B. pneumoniae (Friedländer).}

Theobald Smith (1891) speaks of this organism as a bacillus giving general turbidity in broth, acid and clot in milk, not liquefying gelatine, and fermenting glucose, lactose, and cane-sugar. $\frac{\mathrm{H}}{\mathrm{CO}_{2}}=\frac{1+}{1}$.

Grimbert (1896) says that the Friedländer bacillus is found in water much more frequently than is generally imagined. Like $B$. coli it is Gram-negative, does not liquefy gelatine, and ferments lactose. It does not produce indol and is non-motile. He examined six strains and divided them into three groups :-

Group I. Ferments glucose, arabinose, raffinose, dextrin, mannite, maltose, cane-sugar, galactose, and lactose, but not glycerine, dulcite, or erythrite.

Group II. All these substances are decomposed except dulcite and erythrite.

Group III. Erythrite alone is not attacked.

Hewlett (1902) says the morphology is variable, the bacillus is nonmotile, Gram-negative, and non-liquefying. Indol is not formed, milk is acidified and clotted. A copious, viscid, greyish growth appears on agar. On gelatine it forms a thick, white, shining, porcelain-like growth, and in stab gelatine culture the well-known "nail" growth.

Muir and Ritchie (1902) describe it as a short rod with blunt rounded ends, Gram-negative. It produces acid, with or without clot in milk, and a white, shiny, viscid growth on agar. The gelatine colonies are raised white discs. A stab culture shows the "nail" growth. Gelatine is not liquefied. Fermentation occurs in dextrose, lactose, maltose, dextrin, mannite, and may, or may not, occur in glycerine.

Clairmont (1902) gives the following characters. A non-motile bacillus giving the usual growths on agar, gelatine, and potato ; general turbidity in broth; acid but no clot in milk; and fermenting glucose, lactose, and cane-sugar.

Lehmann and Neumann (1904) describe it as a short, round-ended, non-motile, non-sporing, Gram-negative rod, and a facultative anaerobe. The gelatine colonies are round, soft, white, and slimy looking. A gelatine culture is "nail-like." In broth it produces general turbidity, with a slimy deposit, and the fluid becomes somewhat viscid. Milk is acidified and usually no coagulation occurs within 20 days, but clotting may occur. The production of indol is slight. It is identical with or closely related to the B. capsulatus of Pfeiffer. 
It would appear then that the B. pneumoniae (Friedländer) might be described as a non-motile, non-liquefying, Gram-negative, facultative anaerobic bacillus which produces acid in milk, with or without clotting, and ferments glucose, lactose, and cane-sugar. In the blood of experimental animals it is frequently seen to have a capsule.

\section{B. cloacae (Jordan).}

Theobald Smith (1895) says the B. cloacae is a widely-distributed, motile, strongly fermenting bacillus which gives a reaction with lactose very similar to that of coli. In glucose broth the gas-production amounts to $90 \%-100 \%$ of the closed arm of the fermentation tube and the ratio of $\mathrm{H}$ to $\mathrm{CO}_{2}=1: 2$ or 3 .

Ford (1901) describes the typical $B$. cloacue as a motile, facultative anaerobe, fermenting dextrose, lactose, and cane-sugar, producing indol, giving general turbidity in broth, and acid and clot in milk. A second variety ferments dextrose and lactose but not cane-sugar, and does not produce indol. A third form attacks glucose only of the three sugars named, produces indol, and acidifies milk without clotting it. A fourth kind does not act upon any of the sugars, does not form indol, but clots milk. All four varieties liquefy gelatine, casein, and blood serum, and all are motile.

Irons (1902) mentions that it produces acid and clot in milk, liquefies gelatine, gives rise to acid and gas in dextrose and cane-sugar with gas ratio $\mathrm{H}<\mathrm{CO}_{2}$, and gas in lactose with a varying ratio.

Jordan (1903) writes that it is a motile bacillus fermenting dextrose and cane-sugar, which may or may not act on lactose. Indol production varies, as also does the liquefaction of blood serum and of casein. Only very rarely does it not liquefy gelatine, but the liquefaction may take $30-40$ days.

Lehmann and Neumann (1904) quoting Theobald Smith (1893) describe it as a motile bacillus, liquefying gelatine, producing acid and clot in milk in 8 days, producing much gas in glucose and cane-sugar, i.e., $50-95 \%, \frac{\mathrm{H}}{\mathrm{C}} \overline{\mathrm{O}_{2}}=\frac{1}{2}$. The gas-production in lactose is slow.

The $B$. cloacae (Jordan) then might be described as an actively motile, Gram-negative, facultative anaerobic bacillus, fermenting glucose and cane-sugar, and maybe lactose, producing acid and clot in milk, and which almost invariably liquefies gelatine, and may, or may not, also liquefy blood serum and casein.

The biological characters ascribed to these five organisms by the 
various observers mentioned are best appreciated when tabulated for comparison :--

\begin{tabular}{|c|c|c|c|c|c|c|}
\hline & Glucose & Lactose & Canè-sugar & Milk & Indol & Motility \\
\hline B. coli & + & + & \pm & $A+C^{1}$ & + & \pm \\
\hline $\begin{array}{l}\text { B. lactis aerogenes } \\
\text { (Escherich) }\end{array}$ & + & + & + & $\mathrm{A}+\mathrm{C}$ & \pm & - \\
\hline B. acidi lactici (Hüppe) & ) + & + & - & $A+C$ & + & - \\
\hline $\begin{array}{l}\text { B. pneumoniae } \\
\text { (Friedländer) }\end{array}$ & + & + & + & $A \pm C$ & $\mp$ & - \\
\hline B. cloacae (Jordan) & + & \pm & + & $\mathrm{A} \mp \mathrm{C}$ & \pm & + \\
\hline
\end{tabular}

It is obvious that, if reliance is placed solely upon the reactions given above, these organisms may be said to be closely related; and it is not surprising that by some the B. acidi lactici (Hüppe) and B. lactis aerogenes (Escherich) should be considered identical and practically nonmotile forms of the $B$. coli, or that by others the B. lactis aerogenes is taken to be the same organism as the $B$. pneumoniae (Friedländer). Theobald Smith differentiates these bacilli by the amount of gas produced and by the "gas ratio," and his lead is followed by most of the American bacteriologists. But these distinguishing points are not universally accepted as of value.

With the idea of, if possible, finding further points of difference I have tested the action of these and certain other organisms upon 14 carbohydrates and alcohols; have measured the amount of gas produced and the "gas-ratio," and have noted the appearance of Voges and Proskauer's reaction. The results are set out in the following table, and I desire to take this opportunity of tendering my hearty thanks to those who have so kindly sent me cultures.

It is the universal opinion that with the exception of $B$. cloacae and B. proteus none of these organisms liquefy gelatine, and that none of them stain by Gram's method. It has not been thought necessary to give any description of the morphology nor of the growths on agar, gelatine, or potato.

The "caustic potash red reaction" "was first mentioned by Voges and Proskauer (1898) in a paper on the "Bacteria of Haemorrhagic Septicaemia." They describe it thus (speaking of a Schweinepest bacillus isolated by Voges): "On the addition of caustic potash we observed a new and interesting colour reaction. If the tube be allowed to stand for 24 hours and longer at room temperature, after the addition of the potash, a beautiful fluorescent colour, somewhat similar to that of

1 This is the reaction referred to on p. 337.

Journ. of Hyg. $v$ 


\section{0
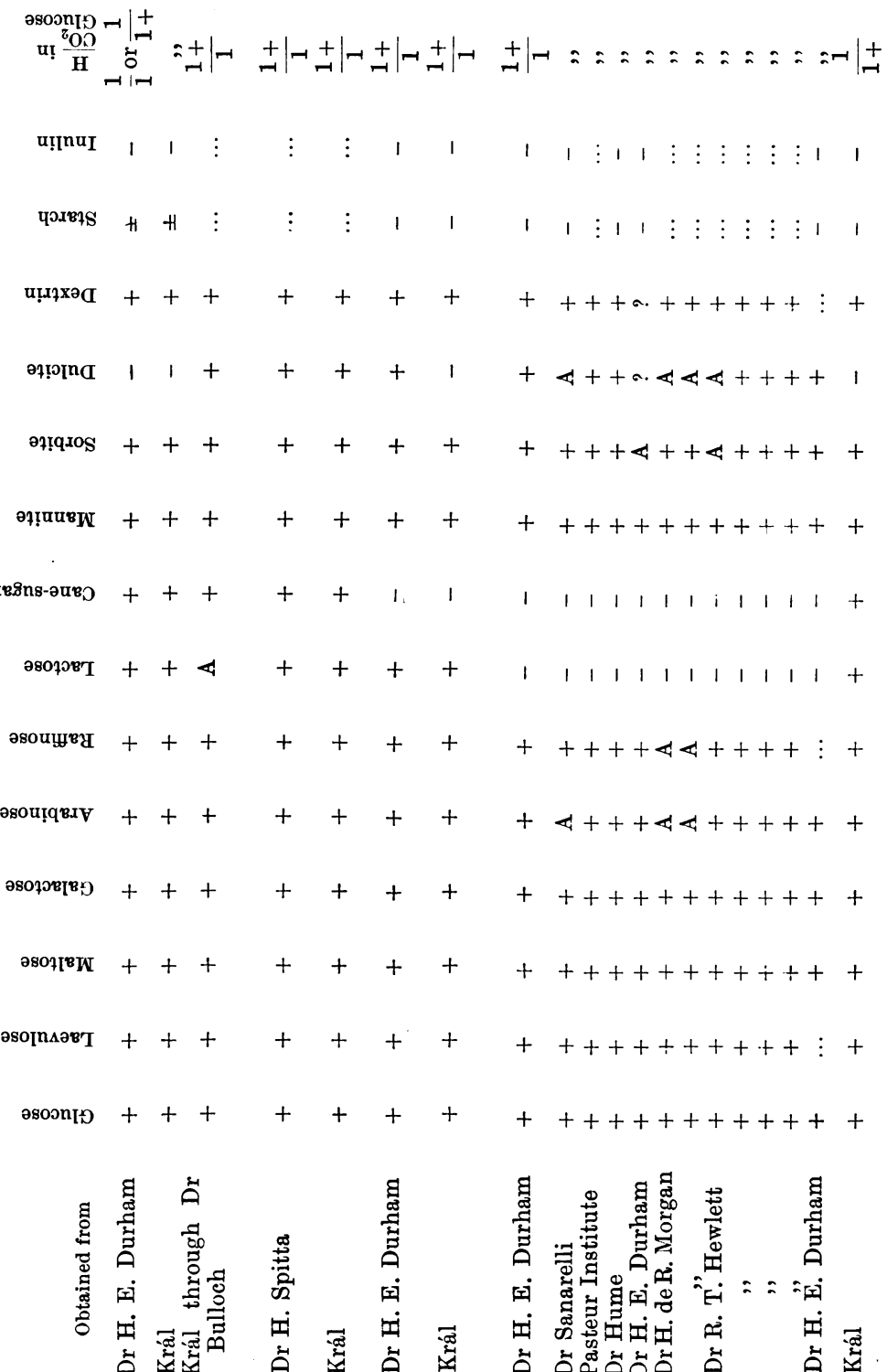

20

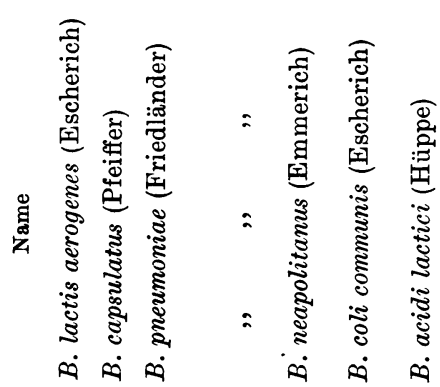

踣 |xं

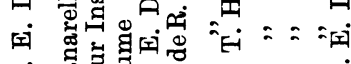

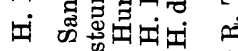

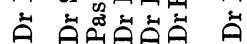

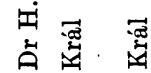
药
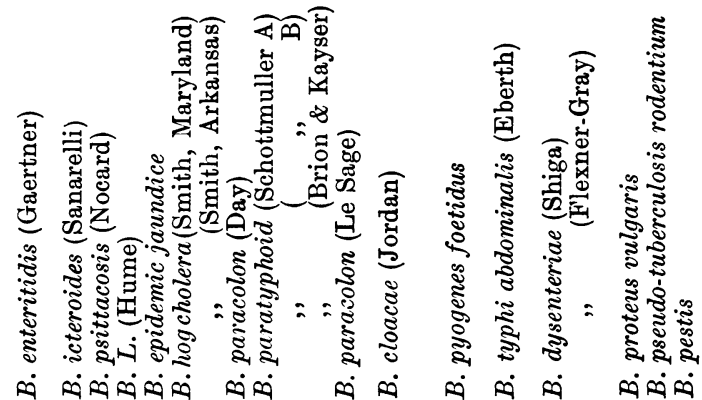
a dilute alcoholic solution of eosin, forms in the culture fluid, particularly at the open end of the tube exposed to the air. We have investigated a few of the properties of this colouring substance, which is not produced by the action of the alkali on the sugar, and have found that it is fairly resistant to the action of the external air. After a time, however, it becomes paler, and finally gives place to a dirty greenish-brown. Prolonged boiling does not affect the intensity or nuance of the colour. We attempted to extract the substance by means of ether and of amyl alcohol but no trace passed into these solvents. Acetic acid changes the tint into a reddish-yellow. The isolation of the colouring substance was not successful owing to the quantity present being too small. We are compelled at present to consider this new potash reaction as specific for the bacillus in question as none of the remaining bacteria, notwithstanding the variety of culture media used, gave it. Neither does the Bacterium coli communis give the reaction, so that we have here a further most valuable means of differentiation from these inhibitants of the intestine." The bacillus referred to as giving this reaction was one which fermented all the carbohydrates and alcohols in which it was grown, which included glucose, lactose, cane-sugar, and mannite, and thus differed from the other varieties of swine-plague and hog-cholera which have been described.

Durham (1900-1901) refers to this reaction and states that it may appear within a few hours after adding the potash (vide supra B. lactis aerogenes). Freeland How, junior (1904), in "Notes on B. coli" refers to those organisms which produce a red colour in the closed arm when standing 24 hours after the addition of potash, and says "just what produces this red colour is not known," and "if it were possible to determine the species to which a culture characterised by this colour belongs it would be of decided advantage to bacteriologists engaged in water analysis," and "the colour is destroyed by the addition of $\mathrm{H}_{2} \mathrm{SO}_{4}$ and restored by adding an alkali."

As will be seen from the table this reaction appears to obtain only in the case of the $B$. lactis aerogenes group and $B$. cloacae group, thus entirely confirming Durham's observation that it was a point of difference between the aerogenes group and the coli enteritidis and typhosus groups. It also helps to distinguish the B. pneumoniae (Friedländer) from the $B$. lactis aerogenes.

For this test it is best to use a fermentation tube, though it may be performed in an ordinary test-tube. The colour closely resembles that of a $0.2 \%$ solution of rosolic acid in $50 \%$ alcohol and water. 
Now if we for the present neglect the question of motility and restrict our consideration to the lactose fermenting organisms solely, a glance at the table above shows that the differentiating points have reference to :-

(1) the fermentation, or otherwise, of cane-sugar and dulcite,

(2) the gas-ratio,

(3) the appearance, or non-appearance, of the "Kalilaugeroth-reaktion " of Voges and Proskauer.

And so, just for the sake of classification in these experiments, the organisms isolated have been divided arbitrarily into four groups according as they do, or do not, ferment cane-sugar and dulcite :-

Group 1 containing these organisms which are cane-sugar - dulcite -

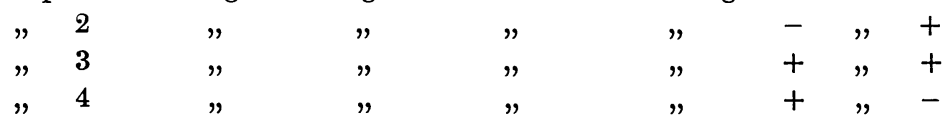

The - sign meaning that the organism has no action, and the + sign denoting the formation of acid and gas.

Without implying that all the organisms in Group $\mathbf{1}$ are identical one may speak of them as conforming in fermentative properties to the type of $B$. acidi lactici (Hüppe). Similarly the B. coli communis (Escherich) may be taken as the fermentative type of Group 2, and the $B$. neapolitanus or B. pneumoniae (Friedländer) as representing Group 3. As regards Group 4 it will be seen from the results given below that this group may be subdivided into :-

Sub-Group 1. ? B. coli ${ }^{1}$. No liquefaction of gelatine ; absence of Voges and Proskauer reaction.

"2. B. lactis No liquefaction of gelatine ;

aerogenes. presence of Voges and Proskauer reaction.

" 3. B. cloacae. Liquefaction of gelatine or casein ; presence of Voges and Proskauer reaction.

" 4. Bacillus? Liquefying gelatine, and producing a yellow pigment.

1 The pathogenic Bacillus coscoroba (Ann. de l'Institut Pasteur, 1900) conforms to this type. 


\section{Section III.}

\section{Effect of Environment upon Biological Characteristics.}

It is not an uncommon experience in laboratory work to find that a stock organism has temporarily lost one or more of its characters, e.g., indol or gas production, or the clotting of milk, and that repeated subcultivation soon causes the organism to resume its former vigour. These temporary enfeeblements are generally said to be due to "unfavourable environment," and it is supposed that a continuation of such unfavourable conditions may cause the change in characteristics to become permanent and thus give rise to a new variety. It might be said that Group 1 was in this way derived from the other groups, and therefore it was considered necessary to enter a little into this question. Jordan (1901) speaking of coli in river water says:-_" It is quite possible that some bacilli may become so disguised by prolonged aquatic life as to be no longer recognisable by the methods used"; but "it is always possible to recover coli bacilli possessed of typical gas-producing qualities from sewage and from polluted river-waters that have been stored for some weeks in glass bottles in the laboratory." "In one instance we have found colon bacilli yielding typical gas production in a 1/1,000 dilution of sewage that had been standing in a bottle for $\mathbf{4 2}$ days, and in another case we have found them six months after the sewage had been collected."

Horrocks (1903) planted agar emulsions of B. coli communis (Escherich) on various samples of soils and examined the cultural reactions from time to time. The bacillus was isolated unchanged from a rich loam at the end of a month, from a virgin loam at the end of six weeks, from a virgin sandy soil at the end of 60 days. He comes to the conclusion that $B$. coli tends to die out in soil, and that the greatest duration of life is about 90 days. He also added emulsions of the same organism to various waters, which were, like the soils, kept at room temperature. From deep well-waters the $\dot{B}$. coli communis was isolated unchanged after 31 days, but after 9 weeks and 3 months there was weakened indol formation and delayed coagulation of milk: from $\mathrm{New}$ River Company's water after 2 months with the same changes: and similarly from sterilised Thames water after 2 to 3 months. He comes to the conclusion that there is no evidence that $B$. coli ever becomes atypical. 
Savage (1905), from experiments with $B$. coli and tidal mud, expresses the opinion that "None of my experiments bear out the idea that $B$. coli in mud, sterilised or unsterilised, alter some of their characters."

Remy (1900) grew B. typhosus and $B$. coli together in neutral bouillon. B. typhosus was isolated after 82 days of life in common. $\mathrm{He}$ says these conditions can modify profoundly the characters of the two organisms, the $B$. typhosus losing its sensibility to agglutinins and the $B$. coli its specific characters, e.g. gas and indol production.

Klotz (1904) in his study of an organism isolated by Adami and Chopin from tap-water and called by him Bacillus perturbans states that after passage through a rabbit there was a temporary loss of gas production in lactose and cane-sugar.

The object of the following experiments was to ascertain whether unsterilised laboratory tap-water would have any influence upon the B. coli communis (Escherich) in the direction of modification of its characters or of a shortening of its life.

A preliminary examination of the tap-water was necessary to obtain its average coli content. For this purpose the tap was allowed to run 5 to 10 minutes before filling a sterile stoppered bottle of about 200 c.c. capacity. Then 1 c.c. of the sample was pipetted off into a tube of bile-salt broth. On three occasions the rest of the sample was concentrated by filtration through a Berkefeld candle, the deposit being scraped off and put into a tube of bile-salt broth. On nine occasions, instead of concentrating the water by filtration, 10 c.c. of a 10 times concentrated bile-salt broth were added to the water in the bottle and the whole incubated at $37^{\circ} \mathrm{C}$. for $24-48$ hours, when a small quantity was used to inoculate a tube of bile-salt broth. When any of the broth tubes showed the production of acid or acid and gas, bile-salt agar plates were made and inoculated from the broth. After incubation at $37^{\circ} \mathrm{C}$. for 24-48 hours a colony was taken and worked through glucose, mannite, lactose, cane-sugar, dulcite, agar, gelatine, broth and litmus milk. Twelve samples were in all examined. B. coli was found once out of 10 times in 1 c.c. and 8 times out of 11 in 200 c.c. It is interesting to note that $B$. coli was not found once in the deposit on the filter-candle, while it was found in almost every case when the concentrated broth was added to the rest of the sample in the bottle. It may, therefore, be accepted that the tap-water used did not usually contain $B$. coli in 1 c.c.

The $B$. coli communis (Escherich) was exposed to the influence of the tap-water in the following old way: A 24 hour broth culture was poured 
into a sterile Pasteur candle, which was plugged with wool and suspended in a jar holding about $1 \frac{1}{2}-2$ litres of tap-water. A similar arrangement was made for the B. typhosus. The jars were kept at room temperature in the dark in a cupboard. From time to time the jars were emptied and filled with fresh water, and the contents of the candles tested for the presence of $B$. coli and B. typhosus respectively. Thus:

3rd day. Water changed.
5th ,
" "
6th " B. coli found inside but not out.
10th , B. typhosus found inside but not out.
19th ", Water changed.
20th " B. coli and B. typhosus present inside the candles.

24th "

27 th ,

" " " " " and water changed.

On this day gelatine plates were poured from the contents of the candles and these showed the presence of innumerable extraneous organisms.

B. coli and B. typhosus found inside in one loopful.

50th " B. coli and B. typhosus inside in 1 c.c. but not outside.

52nd " Water changed.

77th " B. coli inside but not out. B. typhosus apparently dead. Water changed.

81st " No B. typhosus found in the whole of the contents of the filter-candle.

123rd " B. coli found inside in 1 c.c.

266th " Water changed.

267th,$\quad$ B. coli in 1 c.c. inside.

281st " The jar was emptied several days ago and has been allowed to remain so, and the candle to drain itself dry.

310th " The filter-candle is empty and dry. About 300 c.c. of cold boiled distilled water poured into the filter.

311th \# B. coli found in 1 c.c. of the water in the filter. The fermentation of dulcite took a day or so longer than usual, otherwise the organism was unchanged.

329th " The filter has been gradually drying. There is no water in it to-day.

357 th $" 10$ c.c. of sterile water were poured into the filter. It was all absorbed. Then 20 c.c. more were put in, washed round and 2 c.c. used for testing. B. coli was recovered unchanged.

358th , 10 c.c. of sterile water were put into the filter and washed round. Then 1 c.c. was taken out and spread over the surface of a bile-salt lactose-agar plate. This was done with three plates which were incubated at $42^{\circ} \mathrm{C}$.; one plate yielded 2 colonies, another 16 and the third none. One of the colonies was taken and on working out gave B. coli unchanged.

388th " The filter was washed inside with 20 c.c. of sterile water, 1 c.c. of which was tested for the presence of $B$. coli. The result was negative. 
The $B$. coli was not recovered from the $B$.typhosus filter in one single instance and this may, therefore, be considered as a control to the $B$. coli candle.

A further control experiment was performed as follows: The same filter-candle that had been used for the $B$. coli in the previous experiment was cleaned, plugged and sterilised. It was then suspended as before in a jar of tap-water and 10 c.c. of sterile nutrient bouillon was poured into it. The water in the jar was changed from time to time as before and the broth inside the filter tested for $B$. coli. Thus :

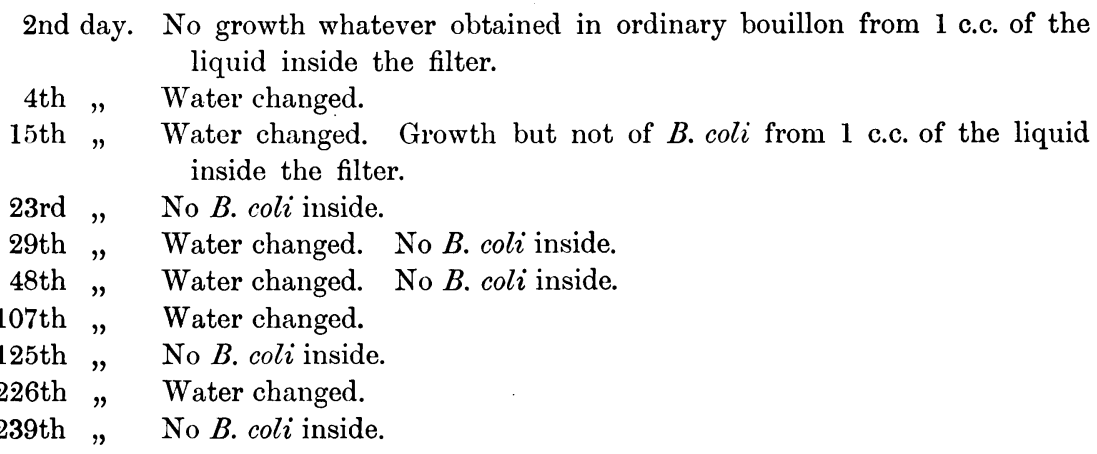

The experiment was discontinued on this day as it was thought that it had been in progress for a sufficiently long time to prove that under the conditions of the experiment any $B$. coli which might be present in the tap-water would not be likely to grow through the filter and multiply to such an extent as to be present in every cubic centimetre of the inner liquid. We may conclude then that none of the $B$. coli isolated in these experiments came from the tap-water filling the jar but they were descendants of the $B$. coli communis culture originally put into the filtercandle.

It is justifiable, therefore, to assert that in this case the $B$. coli communis (Escherich) retained all its characters unchanged after an exposure of 358 days to what was a changing and unfavourable environment, a result distinctly opposed to the idea that $B$. coli communis ever becomes atypical: and tending to confirm the work of Horrocks and Savage. The result also affords presumptive evidence that one group is not derived from another by loss of characteristics on the part of some of its members. 


\section{Section IV.}

Effect of Preliminary Incubation in a Liquid Medium.

In these experiments if any particular organism predominated it might be said that the results of the examination did not represent the true state, as, though all the various organisms might be present in equal numbers, the preliminary incubation in broth might allow one variety to overgrow the others. It became necessary, therefore, to make a few experiments to ascertain the effect of the preliminary incubation upon mixtures of certain known organisms.

Inoculations were, therefore, made from old gelatine cultures of $B$. coli communis (Escherich), B. acidi lactici (Hüppe), B. cloacae (Jordan), B. lactis aerogenes (Escherich), and C. 46 (a yellow liquefier, isolated from cow-dung) into the same tube of bile-salt mannite broth, which was incubated at $37^{\circ} \mathrm{C}$. Next day surface cultivations were made on bile-salt lactose agar plates. Both broth and plates were placed at $37^{\circ} \mathrm{C}$., and next day plates were again made from the broth. We have thus plates made from a mixture after 24 and 48 hours' preliminary incubation in a broth. After each set of plates had been incubated for about 24 hours, 12 colonies were taken from each set and sub-cultured in cane-sugar and dulcite. The results were :-

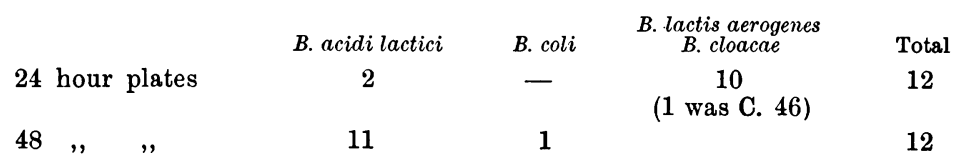

The above experiment was repeated with the difference that nutrient broth cultures about one week old were used to inoculate the tube of bile-salt broth; and 10 colonies only were taken from each set of plates. Result :-

\begin{tabular}{|c|c|c|c|c|}
\hline & B. acidi lactici & B. coli & $\begin{array}{l}\text { B. lactis aerogenes } \\
\text { B. cloacae }\end{array}$ & Total \\
\hline 4 hour plat & - & - & 10 & 10 \\
\hline $48 \quad$, & 2 & - & 8 & 10 \\
\hline
\end{tabular}

A third experiment was made on similar lines using a mixture of $B$. coli communis and B. acidi lactici only. It was considered enough to take 6 colonies from each set of plates. Result:-

24 hour plates

48 ," ,
B. coli 1
B. acidi lactici $5 \quad 6$ 
Further, the B. lactis aerogenes and B. cloacae were inoculated into the same tube of bile-salt mannite broth, and incubated at $37^{\circ} \mathrm{C} . \mathrm{At}$ the end of 24 hours and 72 hours plates were made from the broth on bile-salt lactose agar. After 24 hours at $37^{\circ} \mathrm{C}$. colonies were taken from the plates, sub-cultured into broth and examined. Results :-

$\begin{array}{lccc} & & & \\ 24 \text { hour plates } & \text { B. lactis aerogenes } & \text { B. cloacae } & \text { Total } \\ 72, ", & 9 & 1 & 10 \\ & 10 & 0 & 10\end{array}$

A repetition of this experiment in which plates were made after the broth had been incubated at $37^{\circ} \mathrm{C}$. for 24,48 , and 72 hours yielded

\begin{tabular}{lccccc} 
& \multicolumn{3}{c}{ B. lactis aerogenes } & & B. cloacae \\
24 hours & in the proportion of & 4 & to & 1 \\
$48, "$ & $"$, &, & $30-40$ & to & 1 \\
72, & $"$, & 1 & to & 0
\end{tabular}

The preliminary incubation might, therefore, possibly alter the relative proportions by favouring the growth of the fourth (lactis aerogenes) group; but if the B. coli communis is found, then it is not at all likely that any of the other organisms have been overwhelmed.

\section{Section V.}

As previously mentioned, these experiments were instituted for the purpose of ascertaining the relative frequency of occurrence of certain lactose-fermenting bacilli, but they resolved themselves into a search for the $B$. lactis aerogenes. The change came about in this way. My colleague, Dr A. Harden, was conducting an investigation into the chemical action of these organisms and I passed cultures of the organisms isolated over to him. As organism after organism of the fourth group (p. 3.52) with which I supplied him failed to sutisfy his tests for a B. lactis aerogenes I was led to pay more attention to this organism than to others. But there was also underlying these experiments the idea that a more extended use of carbohydrates and alcohols might possibly bring to light differences between organisms of various origins. It is on this account that the experiments seem somewhat disconnected and that the references to previous work touch upon such a variety of points.

All the organisms isolated had, unless otherwise stated, the following characters in common:-

They were non-sporing, Gram-negative, facultative anaerobic bacilli, 
gave grey-white growths on agar and gelatine, without liquefaction of the latter; produced acid and clotting in milk; general turbidity, with formation of indol, in broth; and fermented glucose, lactose, and mannite with the production of acid and gas. Their action on cane-sugar and dulcite is mentioned in connection with each experiment.

\section{(a) Human faeces.}

Of those who in recent years have examined human faeces there may be mentioned:-

Hans Hammerl (1897) who from his investigations came to the conclusion that whether the food is sterile or not, whether it is purely vegetable or mixed, it has no great influence upon the number of living bacteria in the faeces. The only thing noticed was that when the food was sterile the usual saprophytes commonly found in man's surroundings disappeared from the stools and almost only $B$. coli and $B$. lactis aerogenes were present and fluorescing liquefiers were absent. W. Booker (1897) studying the summer diarrhoea of infants found B. proteus vulgaris, Streptococcus, $B$. coli and B. lactis aerogenes to be the most common organisms. Péré (1898) mentions that the $B$. coli of sucklings attacks cane-sugar, dulcite and glycerine, whereas the $B$. coli of adults does not. Horrocks (1901) compared 80 coli from typhoid stools with 70 coli from normal faeces but could not find any constant characters which distinguished the one kind from the other. Hellström (1901) examined the faeces of new-born children, taking his samples with every aseptic precaution. He found the first meconium was sterile; later air organisms appeared; and later still these latter disappeared and were replaced by the usual intestinal organisms, especially the $B$. coli and B. lactis aerogenes. Ford (1901) states that B. lactis aerogenes is specially found in the small intestine but may pass beyond the iliocaecal valve, where, coming in contact with $B$. coli, it disappears. He also says that $B$. cloacae abounds in the caecum. Kohlbruigge (1901) considers that the small intestine either has no bacteria peculiar to itself or they belong to the $B$. coli group and that the caecum exhibits the typical $B$. coli. Brown (1903) examined the stools of 21 cases of asylum dysentery and isolated the
$B$. enteritidis (Gaertner) in 1 case.
$B$. aerogenes
B. acidi lactici
B. xerosis
,
"
" 
Houston (1902-1903) found there were more than 100 millions but less than 1,000 millions of $B$. coli per gramme of normal human faeces. He isolated and worked out the reactions of 100 of these organisms. As regards indol $99 \%$ were positive; in milk $92 \%$ produced acid and clotting, $8 \%$ acid only; in dulcite $55 \%$ gave acid and gas, while in cane-sugar media $8 \%$ were strongly positive, $22 \%$ feebly positive, $35 \%$ doubtfully negative, and $35 \%$ negative.

We might then expect to be able to isolate $B$. coli and $B$. lactis aerogenes from every sample of faeces. My own experiments do not justify this expectation as regards the latter organism as will be seen from the details of the results.

Just in case it should happen that a variation in the organisms isolated might be caused by the particular kind of broth used for the preliminary incubation, a sample of normal human faeces was taken and a loopful placed in each of 8 tubes of broth. The inoculated tubes were put into the warm incubator till the next day when gelatine plates were poured from each tube. From each set of plates 6 colonies were taken and sub-cultured. Of the 48 organisms thus isolated, 12 grew badly, or not at all, at $37^{\circ} \mathrm{C}$. The remaining 36 were bacilli having the characteristics already mentioned. The action on cane-sugar and dulcite is given in the following table, which also gives the number isolated from each set of plates :

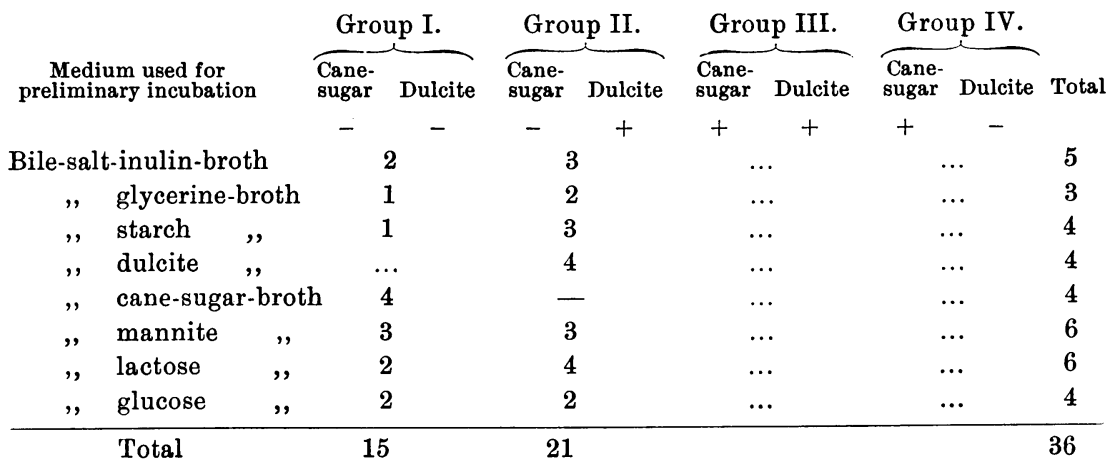

It is noteworthy that not one of the 36 organisms fermented canesugar, glycerine, inulin, or starch. One produced in starch-broth an action which was of such a doubtful character that it has been considered negative. Four were distinctly motile; the rest did not show any motility under the conditions of observation. The growth on potato varied from "invisible" to an abundant yellowish-brown growth. From 
this experiment it may fairly be concluded that the carbohydrate or alcohol in the medium used for preliminary incubation apparently has no selective action upon the organisms growing in it.

In the next experiment samples from the stools of persons in an ordinary state of health were examined. There were 9 samples in all taken from 3 persons; from " $A$ " one sample, from " $B$ " two samples, and from " $C$ " six samples spread over several months. The method adopted consisted in a preliminary incubation in a bile-salt broth followed by agar plates except in the case of the 1st, 3rd, and 4th samples when gelatine plates were used. The results are set out in the following table:

\begin{tabular}{|c|c|c|c|c|c|c|c|c|c|}
\hline \multirow[b]{2}{*}{ Sample } & \multicolumn{2}{|c|}{ Group 1.} & \multicolumn{2}{|c|}{ Group 2.} & \multicolumn{2}{|c|}{ Group 3.} & \multicolumn{2}{|c|}{ Group 4.} & \multirow{2}{*}{$\begin{array}{c}\text { Total } \\
\text { number } \\
\text { isolated }\end{array}$} \\
\hline & $\begin{array}{l}\text { Cane- } \\
\text { sugar }\end{array}$ & Dulcite & $\begin{array}{l}\text { Cane- } \\
\text { sugar }\end{array}$ & Dulcite & $\begin{array}{l}\text { Cane- } \\
\text { sugar }\end{array}$ & Dulcite & $\begin{array}{l}\text { Cane- } \\
\text { sugar }\end{array}$ & Dulcite & \\
\hline & - & - & - & + & + & + & + & - & \\
\hline 1 & \multicolumn{2}{|c|}{2} & \multicolumn{2}{|c|}{1} & \multicolumn{2}{|c|}{$\ldots$} & \multicolumn{2}{|r|}{$3^{*}$} & 6 \\
\hline 2 & \multicolumn{2}{|c|}{12} & \multicolumn{2}{|c|}{$\ldots$} & \multicolumn{2}{|c|}{$\ldots$} & \multicolumn{2}{|c|}{$\ldots$} & 12 \\
\hline 3 & \multicolumn{2}{|c|}{$\ldots$} & \multicolumn{2}{|c|}{1} & \multicolumn{2}{|c|}{2} & \multicolumn{2}{|c|}{$\ldots$} & 3 \\
\hline 4 & \multicolumn{2}{|c|}{2} & \multicolumn{2}{|c|}{$\ldots$} & \multicolumn{2}{|c|}{2} & \multicolumn{2}{|r|}{$1^{* *}$} & 5 \\
\hline 5 & \multicolumn{2}{|c|}{$\ldots$} & \multicolumn{2}{|c|}{2} & \multicolumn{2}{|c|}{4} & \multicolumn{2}{|r|}{4} & 10 \\
\hline 6 & \multicolumn{2}{|c|}{4} & \multicolumn{2}{|c|}{1} & \multicolumn{2}{|c|}{2} & \multicolumn{2}{|r|}{3} & 10 \\
\hline 7 & \multicolumn{2}{|c|}{$\cdots$} & \multicolumn{2}{|c|}{10} & \multicolumn{2}{|c|}{$\ldots$} & \multicolumn{2}{|c|}{$\ldots$} & 10 \\
\hline 8 & \multicolumn{2}{|c|}{3} & \multicolumn{2}{|c|}{2} & \multicolumn{2}{|c|}{6} & \multicolumn{2}{|r|}{1} & 12 \\
\hline 9 & 10 & & .. & & & & &.. & 10 \\
\hline Total & 33 & & 1 & & & & & 12 & 78 \\
\hline
\end{tabular}

Thus we find all four groups present in ordinary faeces with a majority in favour of the two first groups. It is striking that such a small number of the $B$. lactis aerogenes should be isolated by this method considering that the organism grows well on these media and is accepted as being so universally present in faeces. Sample No. 9 was from a liquid stool following the administration of Hunyadi-Janos Water. In the case of sample 8 plates were made after incubation periods of 1 , 2,4 , and 6 hours with the idea of ascertaining whether any particular organism preponderated at these times. There was no difference to be made out between the organisms isolated from these plates and those isolated in the usual way after 18-24 hours' preliminary incubation.

The next step was to ascertain whether there was any difference in the kind and relative frequency of the organisms isolated from the stools of cases of diarrhoea or enteric fever which would enable us to 
distinguish them from those of normal faeces. The method was the same as before, agar plates being made in every instance. Each sample was from a separate case.

\begin{tabular}{|c|c|c|c|c|c|c|c|c|c|c|}
\hline \multirow[b]{2}{*}{ Sample } & \multicolumn{2}{|c|}{ Group 1.} & \multicolumn{2}{|c|}{ Group 2.} & \multicolumn{2}{|c|}{ Group 3.} & \multicolumn{2}{|c|}{ Group 4.} & \multirow[b]{2}{*}{ Total } & \multirow[b]{2}{*}{ Case } \\
\hline & $\begin{array}{l}\text { Cane- } \\
\text { sugar }\end{array}$ & Dulcite & $\begin{array}{l}\text { Cane- } \\
\text { sugar }\end{array}$ & Dulcite & $\begin{array}{l}\text { Cane-- } \\
\text { sugar }\end{array}$ & Dulcite & $\begin{array}{l}\text { Cane- } \\
\text { sugar }\end{array}$ & Dulcite & & \\
\hline & - & - & - & + & + & + & + & - & & \\
\hline 1 & & $\ldots$ & & & & 3 & & 4 & 8 & $\begin{array}{l}\text { Diarrhoea; } 10 \text { organisms } \\
\text { isolated, } 2 \text { were of the } \\
B . \text { pyogenes foetidus } \\
\text { type. }\end{array}$ \\
\hline 2 & & 4 & & & & 2 & & & 10 & Diarrhoea. \\
\hline 3 & & $\ldots$ & & & & .. & & . & 10 & Diarrhoea. \\
\hline 4 & & 8 & & & & .. & & & 9 & $\begin{array}{l}\text { Convalescent from en. } \\
\text { teric fever: } 1 \text { month } \\
\text { after commencement } \\
\text { of attack: } B \text {. typhosus } \\
\text { abundantly present. }\end{array}$ \\
\hline 5 & & 8 & & & & 1 & & . & 10 & Enteric fever. \\
\hline 6 & & 1 & & & & 3 & & & 10 & Enteric fever. \\
\hline Total & & 21 & & & & 9 & & 4 & 57 & \\
\hline
\end{tabular}

These results tend to confirm those of Horrocks in showing that there is no marked difference in the character of the organisms of normal and those of diarrhoeic or enteric stools. There seems, however, a distinct preponderance of the first groups. We have again to note the absence of $B$. lactis aerogenes.

In the next experiment the faeces of one person were examined every day for a week. The diet taken during that time was ordinary mixed diet but no unboiled milk was taken. The result of the seven samples is set out below :

\begin{tabular}{|c|c|c|c|c|c|c|c|c|c|}
\hline \multirow[b]{2}{*}{ Sample } & \multicolumn{2}{|c|}{ Group 1.} & \multicolumn{2}{|c|}{ Group 2.} & \multicolumn{2}{|c|}{ Group 3.} & \multicolumn{2}{|c|}{ Group 4.} & \multirow{2}{*}{$\begin{array}{c}\text { Total } \\
\text { number } \\
\text { isolated }\end{array}$} \\
\hline & $\begin{array}{l}\text { Cane- } \\
\text { sugar }\end{array}$ & Dulcite & $\begin{array}{l}\text { Cane- } \\
\text { sugar }\end{array}$ & Dulcite & $\begin{array}{l}\text { Cane- } \\
\text { sugar }\end{array}$ & Dulcite & $\begin{array}{l}\text { Cane- } \\
\text { sugar }\end{array}$ & Dulcite & \\
\hline & - & - & - & + & + & + & + & - & \\
\hline 1 & \multicolumn{2}{|c|}{9} & \multicolumn{2}{|c|}{1} & \multicolumn{2}{|c|}{$\ldots$} & \multicolumn{2}{|c|}{$\ldots$} & 10 \\
\hline 2 & \multicolumn{2}{|c|}{1} & \multicolumn{2}{|c|}{$\ldots$} & \multicolumn{2}{|c|}{1} & \multicolumn{2}{|c|}{8} & 10 \\
\hline 3 & \multicolumn{2}{|c|}{3} & \multicolumn{2}{|c|}{$\ldots$} & \multicolumn{2}{|c|}{2} & \multicolumn{2}{|c|}{5} & 10 \\
\hline 4 & \multicolumn{2}{|c|}{1} & \multicolumn{2}{|c|}{8} & \multicolumn{2}{|c|}{1} & \multicolumn{2}{|c|}{$\ldots$} & 10 \\
\hline 5 & \multicolumn{2}{|c|}{$\ldots$} & \multicolumn{2}{|c|}{6} & \multicolumn{2}{|c|}{4} & \multicolumn{2}{|c|}{$\ldots$} & 10 \\
\hline 6 & \multicolumn{2}{|c|}{$\ldots$} & \multicolumn{2}{|c|}{7} & \multicolumn{2}{|c|}{3} & \multicolumn{2}{|c|}{$\ldots$} & 10 \\
\hline 7 & .. & & \multicolumn{2}{|c|}{10} & \multicolumn{2}{|c|}{$\cdots$} & \multicolumn{2}{|c|}{$\ldots$} & 10 \\
\hline Total & \multicolumn{2}{|c|}{14} & \multicolumn{2}{|c|}{32} & \multicolumn{2}{|c|}{11} & \multicolumn{2}{|c|}{13} & 70 \\
\hline
\end{tabular}

In this case the only point of interest lies in the relatively small number of the first group present. This result should be considered in connection with the examination of cats' faeces (p. 367). 
If we take the result of the examination of human faeces as a whole, we find that 23 samples of faeces have been analysed from which 241 lactose-fermenting organisms have been isolated, of which 83 , or $34 \%$, belong to the first group, 93 or $38 \%$ belong to the second group, 36 or $15 \%$ belong to the third, and 29 or $12 \%$ belong to the fourth. Only 4 organisms out of 241 were shown definitely to belong to the $B$. lactis aerogenes type. The $B$. cloacae was not isolated in one instance. It must be noted that the Voges and Proskauer reaction was not made use of in these experiments. The cane-sugar fermenting bacilli numbered 65 while the non-cane-sugar fermenters reached a total of 176 , a proportion which is opposed to the statement that the cane-sugar fractors are the more numerous organisms.

\section{(b) Animal faeces.}

Up to the present no differentiating points have been discovered which would enable us to distinguish between the faecal bacteria of the various domesticated animals, or between these and those of human excreta, similar organisms having been found in all. Thus Smith (1891) found in swine faeces bacilli which gave general turbidity in broth, acid and clot in milk, did not liquefy gelatine, and fermented glucose, canesugar and lactose. The gas-reactions were similar to those of the B. pneumoniae (Friedländer). Dyer and Keith (1894) found no difference between human and animal coli. In horse-dung the most common organism was $B$. equi intestinalis which does not grow on agar at $20^{\circ} \mathrm{C}$., reddens litmus-lactose-agar, and clots milk but produces no gas. Lembke (1896) examined dog faeces under varying diets, e.g. bread, meat, fat, and mixed diets. The experiments extended over 65 days and 81 samples of faeces were examined. Only one species of organism was always present, i.e. B. coli. He describes a

B. coli anindolicum: a motile bacillus which produces no indolgas in glucose $30 \% ; \underset{\mathrm{CO}_{2}}{\mathrm{H}}=5 / 3$; lactose $30 \%, \frac{\mathrm{H}}{\mathrm{CO}_{2}}=4 / 3$; milk is acidified and clotted.

and

B. coli anaerogenes: a non-motile indol-producing bacillus, acidifying and clotting milk but producing only acid in glucose and lactose.

Horrocks (1902) examined the dejecta of flies, sheep, and rabbits 


\section{$364 \quad$ Lactose-Fermenting Bacteria in Faeces}

and found typical B. coli communis to be present in all of them. He cites Moore and Wright as having examined 45 cultures of $B$. coli isolated from domesticated animals and having found 23 to be negative towards cane-sugar and 22 positive. E. Heinick (1903) examined bacteriologically the intestinal canal of 23 pigs. Of the organisms present only $B$. coli and $B$. lactis aerogenes occurred regularly. B. coli were the most numerous by far and were identical with human coli. $B$. lactis aerogenes occurred in almost equal numbers. $B$. coli were most numerous in the small gut and caecum, but were often overgrown in the rectum by $B$. lactis aerogenes. This last statement is just the contrary to Ford's conclusion concerning the fate of lactis aerogenes in the human caecum.

My own experiments include the examination of five samples of faeces from the horse and six from the cow and calf. The methods used were the same as in the case of human excreta and the results are given in the following tables:

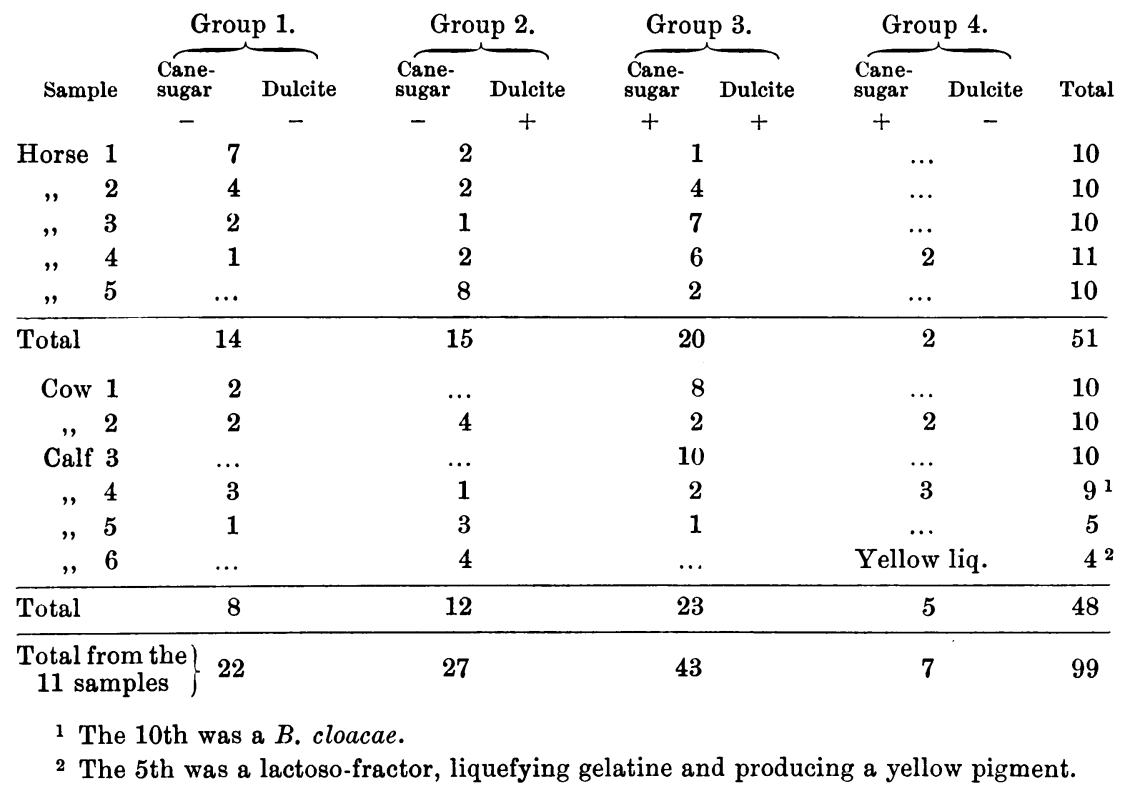

In both kinds of dung the members of the third group corne into greater prominence than in the case of human faeces. Beyond this there is no point of difference. The organisms give just the same reactions as those of human origin. None of the bacilli of Group 4 were identified as being of the $B$. lactis aerogenes type. 
As human enteric stools had been examined there was interest in examining the faeces of animals that had been inoculated with typhoid toxine, which I was enabled to do through the kindness of Dr Allan Macfadyen.

Rabbit No. 1. Intravenous injection of sterile typhoid bacillus cell-juice. Diarrhoea, death.

Rabbit No. 2. Intravenous injection of sterile typhoid bacillus cell-juice. Diarrhoea, death in 5 days.

Rabbit No. 3. Intravenous injection of chloroformed typhoid bacillus cell-juice, death in 3 days.

\begin{tabular}{|c|c|c|c|c|c|c|c|c|c|}
\hline \multirow[b]{2}{*}{ Sample } & \multicolumn{2}{|c|}{ Group 1.} & \multicolumn{2}{|c|}{ Group 2.} & \multicolumn{2}{|c|}{ Group 3.} & \multicolumn{2}{|c|}{ Group 4.} & \multirow[b]{2}{*}{ Total } \\
\hline & $\overparen{\begin{array}{l}\text { Cane- } \\
\text { sugar }\end{array}}$ & Dulcite & $\begin{array}{l}\text { Cane- } \\
\text { sugar }\end{array}$ & Dulcite & $\begin{array}{l}\text { Cane- } \\
\text { sugar }\end{array}$ & Dulcite & $\begin{array}{l}\text { Cane- } \\
\text { sugar }\end{array}$ & Dulcite & \\
\hline & - & - & -. & + & + & + & + & - & \\
\hline No. 1 & \multicolumn{2}{|c|}{1} & \multicolumn{2}{|c|}{$\ldots$} & \multicolumn{2}{|c|}{1} & \multicolumn{2}{|c|}{8} & 10 \\
\hline 2 & \multirow{2}{*}{\multicolumn{2}{|c|}{$\cdots$}} & \multirow{2}{*}{\multicolumn{2}{|c|}{$\ldots$}} & \multirow{2}{*}{\multicolumn{2}{|c|}{$\cdots$}} & \multicolumn{2}{|c|}{10} & 10 \\
\hline 3 & & & & & & & & & 10 \\
\hline Total & \multicolumn{2}{|c|}{2} & \multicolumn{2}{|c|}{8} & \multicolumn{2}{|c|}{1} & 1 & & 30 \\
\hline
\end{tabular}

An examination was also made in the case of a monkey which developed diarrhoea and died after being inoculated by Dr Macfadyen with typhoid bacillus cell-juice. The result was:

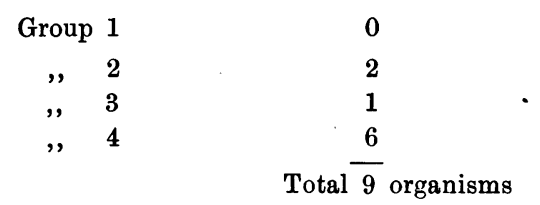

and two other organisms which gave the reactions of B. pyogenes foetidus. There was isolated at the same time a short non-motile Gram-negative bacillus which gave grey-white growths on agar and gelatine without liquefaction, produced general turbidity in broth, acid only in milk, and in glucose and mannite, while lactose, cane-sugar, and dulcite were unaffected. This organism was clumped in a dilution of 1 in 200 by a dysentery serum which agglutinated its own bacillus up to 1 in 800 .

\section{(c) Milk.}

Four samples of milk were examined with the object of ascertaining whether (1) the B. acidi lactici (Hüppe) or the B. lactis aerogenes (Escherich) was present in relatively larger numbers than the organisms of the other groups, and (2) whether, considering that milk is especially 
liable to contamination by cow-dung, the lactose fermenters would be present in proportions similar to those of cow faeces. The examination was conducted in the same way as before.

\begin{tabular}{|c|c|c|c|c|c|c|c|c|c|}
\hline \multirow[b]{2}{*}{ Sample } & \multicolumn{2}{|c|}{ Group 1.} & \multicolumn{2}{|c|}{ Group 2.} & \multicolumn{2}{|c|}{ Group 3.} & \multicolumn{2}{|c|}{ Group 4.} & \multirow[b]{2}{*}{ Total } \\
\hline & $\begin{array}{l}\text { Cane- } \\
\text { sugar }\end{array}$ & Dulcite & $\begin{array}{l}\text { Cane- } \\
\text { sugar }\end{array}$ & Dulcite & $\begin{array}{l}\text { Cane- } \\
\text { sugar }\end{array}$ & Dulcite & $\begin{array}{l}\text { Cane- } \\
\text { sugar }\end{array}$ & Dulcite & \\
\hline & - & - & - & + & + & + & + & - & \\
\hline 1 & \multicolumn{2}{|c|}{3} & \multicolumn{2}{|c|}{4} & \multicolumn{2}{|c|}{3} & \multicolumn{2}{|c|}{$\ldots$} & 10 \\
\hline 2 & \multicolumn{2}{|c|}{5} & \multicolumn{2}{|c|}{1} & \multicolumn{2}{|c|}{1} & \multicolumn{2}{|c|}{3} & 10 \\
\hline 3 & \multirow{2}{*}{\multicolumn{2}{|c|}{5}} & \multirow{2}{*}{\multicolumn{2}{|c|}{1}} & \multicolumn{2}{|c|}{4} & \multirow{2}{*}{\multicolumn{2}{|c|}{$\begin{array}{l}\ldots \\
10\end{array}$}} & 10 \\
\hline 4 & & & & & \multicolumn{2}{|c|}{$\ldots$} & & & 10 \\
\hline
\end{tabular}

There is nothing about this result which resembles that of the faeces of the horse or cow. It might be said almost to be just the reverse, Groups 1 and 4 predominating instead of Nos. 2 and 3.

The percentage of organisms of Group 1 is almost the same as that in human faeces but as regards Group 4 none of the organisms isolated were identified as of the $B$. lactis aerogenes type; one cannot, however, be quite certain upon this point as Voges and Proskauer's reaction was not employed.

The slight differences which appear to exist between the various materials examined are best shown by putting the percentages together in one table.

$\begin{array}{lcccc} & \text { Group 1 } & \text { Group 2 } & \text { Group 3 } & \text { Group 4 } \\ \text { Human faeces } & 34 \% & 39 \% & 15 \% & 12 \% \\ \text { Horse and cow } & 22 & 27 & 43 & 7 \\ \text { Milk } & 32 \cdot 5 & 15 & 20 & 32 \cdot 5 \\ \text { Typhoid (rabbit) } & 7 & 27 & 3 & 63 \\ \text { Cat (on special diet) } & 11 & 41 & 22 & 26\end{array}$

If human and animal faeces are considered together we find that some 500 organisms have been isolated of which about $24 \%$ belong to Group 1, $37 \%$ to Group 2, $22 \%$ to Group 3, and $18 \%$ to Group 4: thus showing that organisms of the B. coli communis type are about $30 \%$ more numerous in faeces than any of the other groups. In this calculation I am anticipating somewhat by including the results of the examination of cat faeces.

(d) Examination of animal faeces when the animal was fed on a partially sterilised diet.

Certain rough experiments which have not been described here suggested that the presence of certain organisms in faeces might possibly 
be associated with the consumption of certain food-stuffs. A cat was therefore confined in a cage and fed upon cooked food. As soon as the food had been boiled it was put while still "boiling hot" into the feeding trough. The drinking water was treated in the same way. No attempt was made to ensure absolute sterility of the food and the surroundings of the animal. Each consecutive stool was examined by the method previously used. The results are detailed below:

\begin{tabular}{|c|c|c|c|c|c|c|c|c|c|c|}
\hline \multirow[b]{2}{*}{ Sample } & \multicolumn{2}{|c|}{ Group 1.} & \multicolumn{2}{|c|}{ Group 2.} & \multicolumn{2}{|c|}{ Group 3.} & \multicolumn{2}{|c|}{ Group 4.} & \multirow{2}{*}{$\begin{array}{c}\text { Total } \\
\text { organisms } \\
\text { isolated }\end{array}$} & \\
\hline & $\overbrace{\begin{array}{c}\text { Cane- } \\
\text { sugar }\end{array}}$ & Dulcite & $\overbrace{\begin{array}{c}\text { Cane- } \\
\text { sugar }\end{array}}$ & Dulcite & $\begin{array}{l}\text { Cane- } \\
\text { sugar }\end{array}$ & Dulcite & $\overbrace{\begin{array}{l}\text { Cane- } \\
\text { sugar }\end{array}}$ & $\underbrace{}_{\text {Dulcite }}$ & & \\
\hline & - & - & - & + & + & + & + & -- & & \\
\hline 1 & 4 & & & 3 & & 3 & .. & & 10 & $\begin{array}{l}\text { First stool passed after com- } \\
\text { mencement of diet of } \\
\text { boiled meat and water. }\end{array}$ \\
\hline 2 & 3 & & & 6 & & 1 & .. & . & 10 & Faeces firm and dark colour- \\
\hline 3 & 8 & & & 2 & & .. & .. & . & 10 & ed,sometimesalmost black. \\
\hline 4 & $\ldots$ & & & .. & & 1 & ( & 9 & 10 & \\
\hline 5 & $\ldots$ & & & .. & & 10 & .. & . & 10 & \\
\hline 6 & $\ldots$ & & & .. & & 10 & .. & . & 10 & $\begin{array}{l}\text { This day diet changed to } \\
\text { boiled milk. }\end{array}$ \\
\hline 7 & $\ldots$ & & & .. & & 1 & & 9 & 10 & $\begin{array}{l}\text { First stool since change of } \\
\text { diet, blackish-brown and } \\
\text { very firm. }\end{array}$ \\
\hline 8 & $\ldots$ & & & .. & & .. & 1 & 0 & 10 & White, soft and slimy faeces. \\
\hline 9 & $\ldots$ & & & .. & & 2 & & 8 & 10 & Greyish or yellowish faeces \\
\hline 10 & $\ldots$ & & & 10 & & .. & .. & . & 10 & $\begin{array}{l}\text { of a soft slimy or mucoid } \\
\text { consistency. }\end{array}$ \\
\hline 11 & $\ldots$ & & & 9 & & 1 & .. & . & 10 & \\
\hline 12 & ... & & & 10 & & ... & .. & . & 10 & $\begin{array}{l}\text { Today diet changed to boiled } \\
\text { meat and water. }\end{array}$ \\
\hline 13 & ... & & & 9 & & 1 & .. & . & 10 & $\begin{array}{l}\text { First faeces since change of } \\
\text { diet, very firm and dark } \\
\text { grey in colour: B. } 28 \text { added } \\
\text { to food. }\end{array}$ \\
\hline 14 & ... & & & 9 & & 1 & .. & . & 10 & Formed greyish-brown stool. \\
\hline Total & 15 & & & 58 & & 31 & 3 & 6 & 140 & \\
\hline 15 & .. & & & 1 & & 4 & & 5 (B. 28) & 10 & $\begin{array}{l}\text { Pultaceous yellowish-brown } \\
\text { faeces. }\end{array}$ \\
\hline 16 & .. & & & 6 & & .. & & 2 (B. 28) & 8 & \\
\hline
\end{tabular}

The animal was then given its freedom in the yard and put on ordinary diet. About two months later a sample was examined and yielded 10 organisms of Group 3. The animal was then again put on a diet of boiled meat and water and after a week or two of this diet a sample analysed gave 10 bacilli belonging to Group 2 .

Bacillus 28 which was added to the food towards the end of the experiment was an organism of the $B$. lactis aerogenes type which had been isolated from human faeces in the earlier experiments. This organism appeared in the cat's faeces 24 hours after administration. No organisms of this type had been found in any of the previous 
14 samples, but the passage of B. 28 through the intestines and its appearance in the faeces shows that if organisms of this type had been present they would have been found by the method used. Worked out in percentages the numbers read:

$$
\begin{array}{ll}
\text { Group 1, } 11 \% & \text { Group 2, 41\% } \\
\text { Group 3, 22\% } & \text { Group 4, 26\% }
\end{array}
$$

showing a distinct preponderance of organisms of the fermentative type of the $B$. coli communis.

The early and complete disappearance of all organisms of the first group and the entire absence of the B. lactis aerogenes is most remarkable.

(e) Examinations at successive intervals of time, of a mixture of tap-water and human faeces.

Bearing in mind that the $B$. lactis aerogenes grows well on bilesalt media and that it is stated to be commonly present in faeces, it is remarkable how small a number of these organisms has been isolated during the course of the previous experiments. It was thought that this might be possibly due to their being present originally in numbers which are small compared with the $B$. coli, and that they might come more into evidence if they had more time to multiply. The following experiment was performed with this idea in view and also for the purpose of ascertaining the changes, if any, which occur in the relative proportions of the four groups when faeces are diluted with water and kept for some time in a flask in the dark at room temperature. A litre flask was filled with tap-water, steamed in Koch's sterilizer for about half-an-hour, allowed to cool, and then inoculated with an amount of human faeces sufficient to cause a distinct turbidity of the whole contents of the flask. About $0 \cdot 1$ c.c. of the mixture was at once rubbed over the surface of three bile-salt lactose-agar plates. After 48 hours' incubation at $42^{\circ} \mathrm{C}$, there was only 1 colony on the three plates. The two sterile plates were re-inoculated from the flask (= sample 1 ), and 0.5 c.c. from the flask was put into bile-salt mannite broth from which after 24 hours' incubation plates were made (= sample 2 ). On the 12 th day 1 c.c. from the flask (previously well shaken) was put into the bile-salt broth and subsequently plated. This formed sample 3:-

Sample 4 was taken on the 23rd day,

$\begin{array}{lllll}" & 5 & & & 30 \text { th day, } \\ " & 6 & " & " & 37 \text { th day, } \\ " & 7 & \# & " & 44 \text { th day. }\end{array}$


In all 75 organisms were isolated and the results are shown in the following tables, the first giving the number in each group which occurred in each sample, and the second giving some details of all the organisms isolated. All the organisms fermented glucose, lactose and mannite with the formation of acid and gas. For obvious reasons more attention was paid to the members of the 4th group than to the rest.

\begin{tabular}{|c|c|c|c|c|c|c|c|c|c|}
\hline \multirow[b]{2}{*}{ Sample } & \multicolumn{2}{|c|}{ Group 1.} & \multicolumn{2}{|c|}{ Group 2.} & \multicolumn{2}{|c|}{ Group 3.} & \multicolumn{2}{|c|}{ Group 4.} & \multirow{2}{*}{$\begin{array}{c}\text { Total } \\
\text { number } \\
\text { isolated }\end{array}$} \\
\hline & $\overbrace{\text { Cane- }}^{\text {sugar }}$ & Dulcite & $\overbrace{\begin{array}{l}\text { Cane- } \\
\text { sugar }\end{array}}$ & Dulcite & $\begin{array}{l}\text { Cane- } \\
\text { sugar }\end{array}$ & Dulcite & $\begin{array}{l}\text { Cane- } \\
\text { sugar }\end{array}$ & Dulcite & \\
\hline & - & - & - & + & + & + & + & - & \\
\hline 1 & & 1 & & 5 & & 2 & & 4 & 12 \\
\hline 2 & & 5 & & 2 & & 1 & & 3 & 11 \\
\hline 3 & &.. & & 3 & &.. & & 4 & 7 \\
\hline 4 & &.. & & 0 & &.. & &.. & 10 \\
\hline 5 & & .. & & 1 & & 1 & & 8 & 10 \\
\hline 6 & & .. & & 5 & & 5 & &.. & 10 \\
\hline 7 & & .. & & 1 & & 1 & & 3 & 15 \\
\hline Total & & 6 & & 77 & & 10 & & 2 & 75 \\
\hline
\end{tabular}

The gas percentages and ratios (Table $\mathrm{C}$, next page) were noted after 3-4 days' incubation except in the case of sample 4 when 6 days were allowed for growth. The numbers given are not necessarily those yielded by the organism when first isolated. Thus :-

\begin{tabular}{|c|c|c|c|c|c|c|}
\hline \multirow[b]{2}{*}{ No. } & \multicolumn{2}{|c|}{ 1st Test } & \multicolumn{2}{|c|}{ 2nd Test } & \multicolumn{2}{|c|}{ 3rd Test } \\
\hline & Gas & $\frac{\mathrm{H}}{\mathrm{CO}_{2}}$ & Gas & $\frac{\mathrm{H}}{\frac{\mathrm{CO}_{2}}{2}}$ & Gas & $\frac{\mathrm{H}}{\mathrm{CO}_{2}}$ \\
\hline 21 & $35 \%$ & $1 / 1$ & $70 \%$ & $2 / 3$ & $80 \%$ & $2 / 3$ \\
\hline 13 & 25 & $4 / 1$ & 12 & $5 / 1$ & 50 & $2 / 1$ \\
\hline 17 & 40 & $2 / 1$ & 20 & $3 / 1$ & 50 & $2 / 1$ \\
\hline 27 & 17 & $2 / 1$ & 80 & $2 / 3$ & 80 & $1 / 2$ \\
\hline 28 & 12 & $4 / 1$ & 80 & $1 / 1$ & 60 & $1 / 1$ \\
\hline 29 & 25 & $2 / 1$ & 70 & $1 / 2$ & 50 & $2 / 3$ \\
\hline 30 & 40 & $1 / 1$ & 80 & $2 / 3$ & 80 & $1 / 2$ \\
\hline 41 & 85 & $2 / 3$ & 55 & $4 / 3$ & & \\
\hline 42 & 85 & $2 / 3$ & 60 & $1 / 1$ & & \\
\hline 43 & 90 & $1 / 2$ & 60 & $1 / 1$ & & \\
\hline 44 & 80 & $2 / 3$ & 55 & $1 / 1$ & & \\
\hline 45 & 85 & $1 / 2$ & 55 & $1 / 1$ & & \\
\hline 46 & 50 & $3 / 2$ & 50 & $1 / 1$ & & \\
\hline 47 & 35 & $11 / 1$ & 60 & $2 / 1$ & & \\
\hline 48 & 45 & $4 / 1$ & 55 & $3 / 1$ & & \\
\hline 61 & 75 & $2 / 3$ & 55 & $1 / 1$ & & \\
\hline 62 & 65 & $2 / 3$ & 40 & $1 / 1$ & & \\
\hline 63 & 55 & $2 / 3$ & 50 & $1 / 1$ & & \\
\hline 9 & 80 & $2 / 3$ & 40 & $1 / 1$ & & \\
\hline 10 & 80 & $2 / 3$ & 55 & $4 / 3$ & & \\
\hline 11 & 75 & $1 / 2$ & 55 & $1 / 1$ & & \\
\hline 12 & 70 & $2 / 3$ & 60 & $1 / 1$ & & \\
\hline
\end{tabular}


370 Lactose-Fermenting Bacteria in Faeces

空

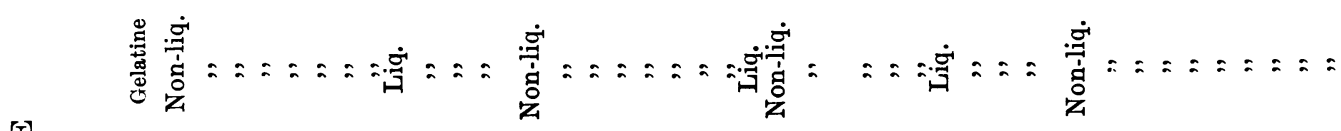

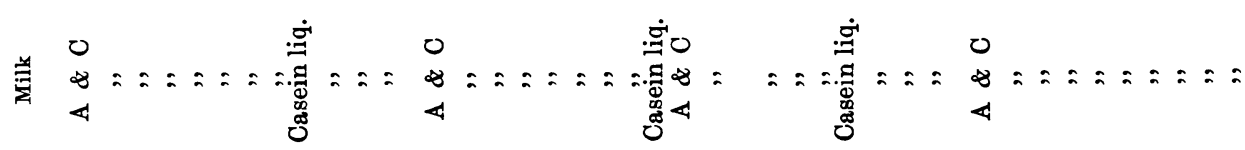

要 $111+1:++11111+1+111+11+i+++1$

㩆

$++++1$

$+$

$+++$

क.

+

1

$+++1 \quad 1 \quad+$

$+++$

吾

氙

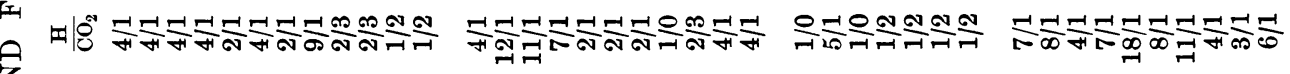

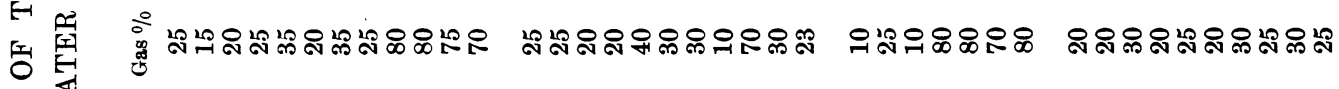

政

落

苛
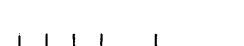

药

s:
क्ष
की

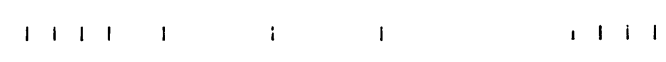

壱

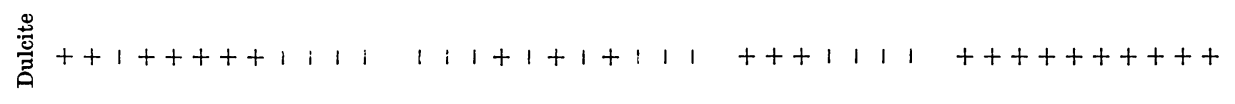

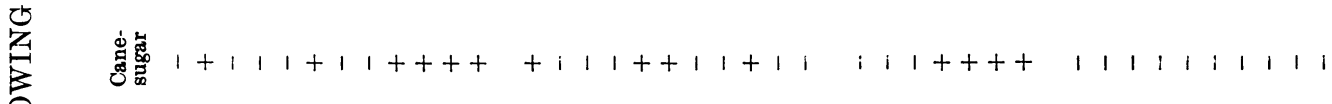

蛋

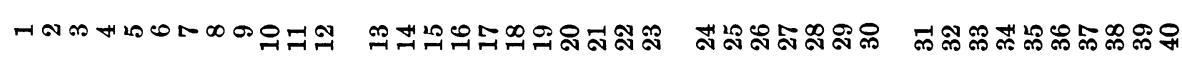

孚
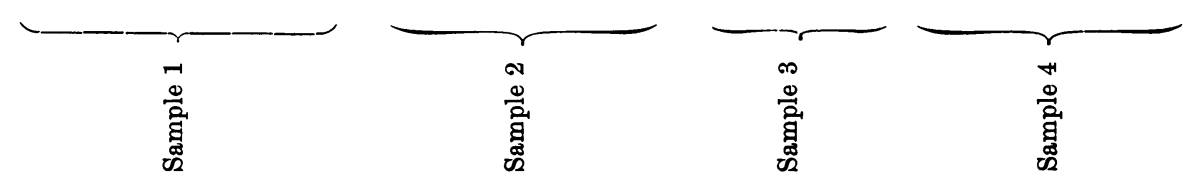


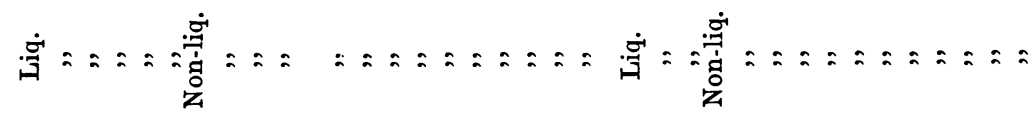

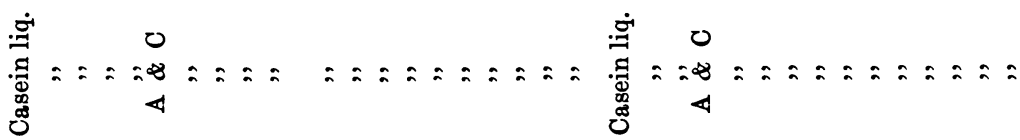

$1111+++11+t+1+t+t+1+t \quad 111++1+111+1+t 1$

$+++++11 \quad+t+$

$+++++11 \quad+t+$

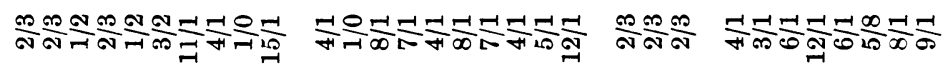

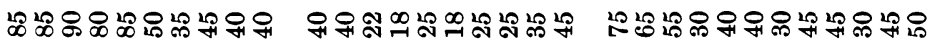

$\begin{array}{llllllll}1 & 1 & 1 & 1 & 1 & 1 & 1 & 1\end{array}$

$\begin{array}{lllllllllll}1 & 1 & 1 & 1 & 1 & 1 & 1 & 1 & 1 & 1 & 1\end{array}$

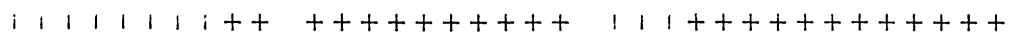

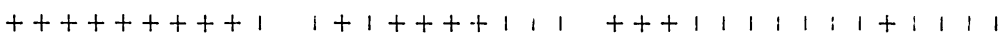

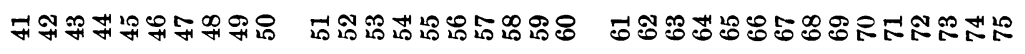

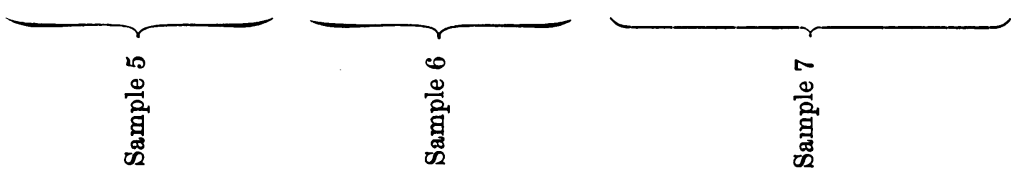


Some organisms were tested four or more times but it is considered unnecessary to give these results. It is apparent that the gas-reaction given by these organisms may vary considerably, and that on occasion an excess of hydrogen over $\mathrm{CO}_{2}$ is not enough to exclude a bacillus from the cloacae group. Voges and Proskauer's reaction, however, was given even where the gas ratio was not typical.

None of the above organisms of the fourth group liquefied blood serum in three weeks.

In litmus milk they all produced acid and caused clotting. Later, it was noticed that the surface layer of some was turning blue and the casein was being dissolved. After 3 months' growth (mostly at room temperature) the surface layer of most was blue, then a layer of turbid yellowish fluid, and at the bottom yellowish softened clot. There was distinct solution of the casein. The only exceptions were Nos. 13, 17, 46,47 , and 48 . In the case of $13,17,47$, and 48 the clot was quite firm, pink above and decolorised below. There was very little fluid. In 46 the clot was pink above and decolorised below but it was not quite so firm as the others and there was more liquid in the tube. There was not, however, any apparent solution of the casein.

In $6 \%$ gelatine none of these organisms caused liquefaction in $5-6$ weeks but when examined at the end of three months it was found that with the exception of $13,17,47$, and 48 all had caused about half an inch of liquefaction. There was no liquefaction whatever in the case of the four bacilli mentioned. Of the 75 organisms isolated we find 22 belonging to the fourth group, and of these 18 are members of the $B$. cloacae group, one differing from the rest in not liquefying casein, and the remaining four may for the present be classed as $B$. coli. We are again struck by the absence of $B$. lactis aerogenes, and this is all the more remarkable from the fact that this sample of faeces was supplied by a person from whose dejecta $B$. lactis aerogenes had been isolated in a previous experiment. Just as in the case of cat faeces, the members of Group 1 cease to appear quite early in the experiment. After 7 weeks' exposure to the conditions of the experiment the second group still occurs in undiminished numbers. 


\section{Section VI.}

Fermentation of Starch and Inulin.

The fermentation of starch or inulin appears to be a property not commonly possessed by these organisms, for 123 (60 from human, 17 from horse, and 26 from cow faeces together with 20 from milk) were tested in inulin without showing any action upon it; and of 133 (95 from human, 20 from horse, and 18 from cow faeces) only 3 showed any action on starch, and these were all of human origin.

This failure to ferment starch on the part of such a large number of organisms, coupled with the small number of bacilli of the $B$. lactis aerogenes group isolated, raised the question as to whether starchfermenting bacteria were usually present in faeces, and suggested the advisability of carrying out one or two experiments from this point of view.

Human faeces. A loopful of human faeces was put into each of two tubes of bile-salt starch broth, which were incubated at $37^{\circ} \mathrm{C}$. In each case there was evident production of acid and gas after 24 hours' growth. From these first two tubes sub-cultures were made into a second pair of starch tubes, and after a day or two from the second pair into a third pair of starch tubes. In none of these sub-cultures was there any production of acid or gas. Plates were also made from one of the first pair and from one of the second pair of tubes and three organisms isolated from each set of plates. None of these organisms caused any change in bile-salt starch broth.

Again, a small quantity of human faeces was put into a tube of ordinary broth. Twenty-four hours' incubation at $37^{\circ} \mathrm{C}$. produced an excellent growth. A loopful of this mixed growth was put into bile-salt starch broth and the tube placed at $37^{\circ} \mathrm{C}$. No change had occurred at the end of 5 days.

Horse faeces were put into bile-salt starch broth at $42^{\circ} \mathrm{C}$. After 48 hours' growth a loopful was transferred to a second tube of starch broth. No change took place in either tube.

Cow faeces. A similar experiment was made with cow faeces with exactly the same result.

To further test this question, tubes of starch broth were inoculated as below and incubated at $37^{\circ} \mathrm{C}$. 


\title{
$374 \quad$ Lactose-Fermenting Bacteria in Faeces
}

No. 1

\author{
B. lactis aerogenes \\ B. coli communis \\ B. acidi lactici \\ no fermentation in 4 days. \\ B. cloacae
}

No. 2

B. lactis aerogenes acid and gas in 48 hours.

No. 3

$\left.\begin{array}{l}\begin{array}{l}\text { B. lactis aerogenes } \\ \text { Horse faeces }\end{array}\end{array}\right\}$ no fermentation in 4 days.

No. 4

B. lactis aerogenes \} ? gas; a sub-culture made into starch gave Cow faeces $\}$ a negative result.

Another experiment was made on similar lines:-

\begin{tabular}{|c|c|c|c|c|}
\hline & Tube 1 & 2 & 3 & 4 \\
\hline Inoculated with & B. lactis aerogenes & $\begin{array}{l}\text { B. lactis aerogenes } \\
+ \text { horse faeces }\end{array}$ & $\begin{array}{l}\text { B. lactis aerogenes } \\
+ \text { cow faeces }\end{array}$ & $\begin{array}{l}\text { B. lactis aerogenes } \\
+ \text { broth culture } \\
\text { of human faeces }\end{array}$ \\
\hline After 3 days at $37^{\circ} \mathrm{C}$. & $?$ any change & acid + gas & acid + gas & ? any change \\
\hline
\end{tabular}

Sub-cultures made into starch-broth from each tube.

After 3 days' incubation acid + gas | ? change | ? change | acid+gas

Sub-cultures made into starch-broth from each tube.

After 3 days' incubation acid+gas | acid+gas | ? I acid+gas

These results justify the conclusion that the fermentation of starch is a test upon which not much reliance can be placed.

\section{Section VII.}

Voges and Proskauer's reaction as a test for the presence of $B$. lactis aerogenes and $B$. cloacae.

This continued failure to isolate the $B$. lactis aerogenes raised doubt as to its constant presence in faeces, and suggested the possibility of using Voges and Proskauer's reaction as a rapid test for the presence of this organism and of $B$. cloacae in various materials, and of thus gaining an idea of the extent of their distribution in nature.

It became, therefore, necessary first to ascertain the effect of growth in mixtures upon the appearance of this reaction. For this purpose the following experiments were performed.

Two fermentation tubes filled with $2 \%$ glucose-broth were inoculated 
with mixtures of organisms as below and incubated at $37^{\circ} \mathrm{C}$. for 3 days. Result :-

Tube No. 1

B. cloacae (Jordan)

B. capsulatus (Pfeiffer)

$B$. lactis aerogenes (Escherich)

B. coli communis (Escherich)

B. acidi lactici (Hüppe)

B. neapolitanus (Emmerich)

B. pneumoniae (Friedländer)

B. proteus vulgaris

B. coli communis

B. acidi lactici

B. neapolitanus

B. pneumoniae

B. proteus vulgaris

$$
\begin{aligned}
& \text { Percentage } \quad \frac{\mathrm{H}}{\mathrm{CO}_{2}} \quad \text { Voges and Pros- } \\
& \text { of gas } \quad \overline{\mathrm{CO}_{2}} \quad \text { kauer's reaction }
\end{aligned}
$$

50

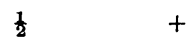

20

f

Again fermentation tubes containing as before $2 \%$ glucose-broth were inoculated as below, and after 48 hours' incubation at $37^{\circ} \mathrm{C}$. yielded as results :-

No. 1

$\frac{\mathrm{H}}{\mathrm{CO}_{2}}$

Voges and Proskauer's reaction

B. capsulatus

$B$. coli communis

B. acidi lactici

$B$. neapolitanus

B. pneumoniae (Friedländer)

\}

B. proteus vulgaris

No. 2

B. lactis aerogenes

B. coli communis etc., etc.

1/1 + after 24 hours.

No. 3

B. cloacae

B. coli communis etc., etc.

? trace after standing 24 hours, + after 48 hours.

No. 4

B. capsulatus (Pfeiffer)

B. proteus vulgaris

? trace after standing 24 hours, + after 48 hours.

No. 5

B. cloacae

B. proteus vulgaris

+ after 24 hours. 
A fresh test was made by inoculating fermentation tubes containing bile-salt cane-sugar broth with rabbit faeces $+B$. lactis aerogenes, rabbit faeces $+B$. cloacae, guinea-pig faeces $+B$. lactis aerogenes and guinea-pig faeces $+B$. cloacae. After 48 hours' incubation at $37^{\circ} \mathrm{C}$, the results were :-

Rabbit faeces $+B$. lactis aerogenes

Rabbit faeces $+B$. cloacae

Guinea-pig faeces $+B$. lactis aerogenes

Guinea-pig faeces $+B$. cloacae

$\begin{array}{ccc}\text { Gas } \% & \frac{\mathrm{H}}{\mathrm{CO}_{2}} & \begin{array}{c}\text { Voges and Pros- } \\ \text { kauer's reaction }\end{array} \\ 40 & 1 / 1 & + \\ 40 & 1 / 1 & + \\ 10 & 1 / 1 & \text { trace } \\ 15 & 2 / 1 & +\end{array}$

Another series of glucose-broth tubes was inoculated with small quantities of the faeces of various animals and placed at $37^{\circ} \mathrm{C}$. After 3 days' incubation the results of growth were :-

$\begin{array}{lccc}\begin{array}{l}\text { Kind of } \\ \text { faeces }\end{array} & \begin{array}{c}\text { Percentage of } \\ \text { gas in closed } \\ \text { arm of tube }\end{array} & \frac{\mathrm{H}}{\mathrm{CO}_{2}} & \begin{array}{c}\text { Voges and Proskauer's } \\ \text { reaction after } \\ 24 \text { hours' standing }\end{array} \\ \text { Rat } & 80 & 1 / 13 & - \\ \text { Donkey } & 90 & 3 / 1 & - \\ \text { Monkey } & 30 & 1 / 5 & \text { trace } \\ \text { Rabbit } & 50 & 3 / 1 & \text { trace ; increased } \\ \text { Mouse } & 5 & 1 / 0 & \text { after } 48 \text { hours } \\ \text { Guinea-pig } & 8 & 1 / 0 & - \\ \text { Goat } & 1 \text { bubble } & 1 / 0 & - \\ \text { Horse } & 3 & 1 / 0 & - \\ \text { Calf } & \text { nil } & & \text { ? trace }\end{array}$

A similar experiment was made with a broth containing $1 \%$ of canesugar instead of glucose. After 5 days' incubation at $37^{\circ} \mathrm{C}$. the results were :-

$\begin{array}{lccr}\text { Dog } & \text { bubble } & 1 / 0 & - \\ \text { Goat } & 10 & 3 / 2 & - \\ \text { Mouse } & 45 & 2 / 3 & - \\ \text { Calf } & \text { bubble } & 1 / 0 & - \\ \text { Rabbit } & 30 & 1 / 3 & - \\ \text { Monkey } & 10 & 2 / 1 & - \\ \text { Guinea-pig } & 80 & 6 / 1 & - \\ \text { Rat } & 75 & 2 / 3 & + \\ \text { Horse } & 12 & 9 / 1 & -\end{array}$

From these results we must conclude that though this test succeeds in artificial mixtures, yet when used with natural mixtures the results are not sufficiently definite to allow us to place absolute reliance upon it as evidence of the presence or absence of the organisms under consideration. 


\section{Summary.}

(1) The fermentation reactions of certain known organisms have been examined and the lactose-fermenters have been arbitrarily divided into four groups according as they do, or do not, decompose cane-sugar and dulcite, and this grouping has been applied to the organisms isolated in the experiments.

(2) Of human faeces 23 samples have been examined and 241 lactose-fermenting bacilli isolated; of animal faeces 25 samples giving 239 organisms; of milk 4 samples and 40 organisms; and of a mixture of tap-water and faeces 7 samples and 75 bacteria.

(3) Of 480 coli-like organisms fermenting lactose isolated from human and animal faeces :-

120 (25 p.c.) belonged to the 1 st group represented by the B. acidi lactici (Hüppe);

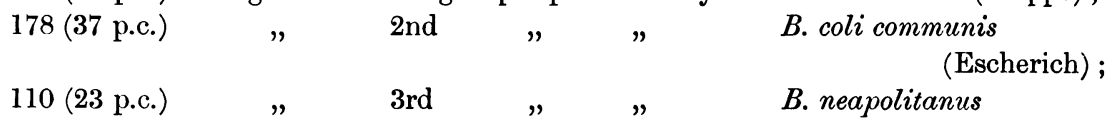

72 (15 p.c. $) \quad " \quad$ (Emmerich);
$\quad " \quad$ th $\quad$ which contains organisms fermenting cane-
sugar but not dulcite

or, to put it more suecinctly 298 (62 p.c.) had no action on cane-sugar, and 182 (38 p.c.) fermented this sugar, and 288 (60 p.c.) decomposed dulcite, while 192 (40 p.c.) did not.

(4) The B. acidi lactici (Hüppe) group in certain circumstances disappeared entirely from the faeces.

(5) In all 625 lactose-fermenting bacilli have been isolated, and of these only 4 have been identified as of the B. lactis aerogenes type and 19 as B. cloacae.

(6) 18 B. cloacae were planted on gelatine and examined from time to time during six weeks when they did not show a trace of liquefaction but there was distinct liquefaction in three months.

(7) The B. coli communis (Escherich) has been exposed for 358 days to the influence of unfavourable environment without losing any of its fermentative characteristics, or its power of clotting milk and producing indol.

(8) Voges and Proskaner's "Kalilauge-roth-reaktion" has been looked for in the cultures of a large number of organisms and has only appeared when organisms of the $B$. lactis aerogenes or $B$. cloacae groups were present. 
(9) At present there is no means of differentiating the lactosefermenting organisms of human from those of animal origin; or those of normal dejecta from those found in enteritis.

(10) B. lactis aerogenes is not the same organism as the B. acidi lactici (Hüppe), and these organisms are not simply non-motile forms of B. coli communis.

(11) Contrary to Pérés statement, there are dulcite-fermenting coli in the faeces of adults as well as of sucklings.

(12) As the $B$. coli communis group seems to be more clearly associated with faeces than the other groups, further research along these lines would in all probability help to place the value of "coli" as an index of pollution upon a sound basis.

(13) As the B. acidi lactici (Hüppe) group sometimes disappears so quickly from the faeces, it may not be of truly faecal origin, or may require such special conditions for its continued growth that it may eventually come to afford evidence as to the nearness or remoteness of pollution.

(14) In the report of the bacteriological examination of a drinking water all the characters of the organisms isolated should be given, and these should include at least the fermentation reactions in glucose, lactose, mannite, cane-sugar, and dulcite, the gas amount and gas-ratio, and the occurrence of Voges and Proskauer's reaction.

\section{REFERENCES.}

Аввотт, А. С. (1902). Principles of Bacteriology, p. 432.

Booker, W. D. (1891). Centralbl. f. Bakt., x. p. 284.

Brown, R. T. (1903). Journ. Royal Army Medical Corps, Vol. I. p. 425.

Clairmont, Paul (1902). Zeitschr.f. Hygiene, Vol. xxxix. p. 1.

"Durham, H. E. (1900-1901). Journ. of Experimental. Medicine, p. 354.

$\checkmark \quad-\quad$ (1898). British Medical Journ., Vol. I. p. 1387.

Dyer and Keith (1894). Centralbl. f. Bakt., I. Ref. xvi. p. 838.

Ehrenfest (1896). Centralbl.f. Bakt., Ref. xx. p. 593.

Elsner (1896). Zeitschr. f. Hyg., xxi. p. 25.

Eyre, J. W. H. (1904). Lancet, Vol. I. p. 648.

Fermi, C. (1898). Centralbl. f. Bakt., Abth. I. xxiII. p. 208.

LFoRD, W. W. (1901). Journal of Med. Research, Vol. vi. p. 211.

Gabritschewsky, G. (1902). Centralbl. f. Bakt., I. Orig. xxxir. p. 256.

Grimbert, L. (1896). Annales de l'Institut Pasteur, Vol. x. p. 708.

(1896). Compt. Rend. Société de Biologie, p. 722.

Grimbert and Legros (1901). Centralbl. f. Bakt., i. Ref. p. 434. Annal. de l'Inst. Pasteur, 1900, xIv. p. 479. 
Grünbaum and Hume (1902). Brit. Med. Journ., Vol. I. p. 1473.

Hammerl, H. (1897). Centralbl.f. Bakt., i. Ref. xxir. p. 706.

Heinick, E. (1903). Centralbl.f. Bakt., I. Ref. xxxiIr. p. 734.

Hellström (1901). Centralbl. f. Bakt., i. Ref. p. 309.

Hewlett, R. T. (1902). Manual of Bacteriology, pp. 280, 314, 485.

Horrocks, W. H. (1903). Journ. of Royal Army Medical Corps, Vol. I. p. 362.

(1901). Journ. of Hyg., Vol. I. p. 202.

Houston, A. C. (1902-1903). Supplement to Rep. of Med. Offic. to Local Govt. Board, p. 511.

How, Freeland (1904). Centralbl. f. Bakt., i. Orig. xxxvi. p. 484.

Irons, E. E. (1902). Journ. of Hy.g., Vol. II. p. 314.

Johnson, G. A. (1904). Journ. of Infect. Diseases, Vol. I. p. 348.

Jordan, E. O. (1901). Journ. of Hyg., Vol. I. p. 295.

(1903). $\quad$ Vol. III. p. 1.

KLOTZ (1904). Journ. of Med. Research, Vol. xI. p. 478.

KohlbR ̈̈GGe, J. H. F. (1901). Centralbl. f. Bakt., I. p. 20.

Kruse (1903). Centralbl. f. Bakt., i. Orig. xxxiv. p. 737.

Lehmann and Neumann (1904). Bacterial Diagnosis, pp. 206, 207, 211, 239, 291.

Lembie (1896). Archiv f. Hyg., xxvi., Centralbl. f. Bakt., I. Ref. xx. p. 615.

MaCConkey and Hill (1901). "Bile Salt Broth." Thompson Yates Lab. Reports, Vol. Iv. Part I. p. 151.

Moore, A. (1902). Brit. Med. Journ., March 22.

Muir and Ritchie (1902). Manual of Bacteriology, pp. 168, 191, 309.

Orlowski (1897). Centralbl. f. Bakt., I. Ref. xxir. p. 134.

Péré, M. A. (1898). Annales de l'Inst. Pasteur, Vol. xir. p. 63.

Prescott, S. G. (1903). C'entralbl. f. Bakt., I. Ref. xxxiIr. p. 279

Radziewsky, A. (1900). Zeitschr. f. Hyg., Vol. xxxiv. p. 369.

Remy (1900). Annales de l'Inst. Pasteur, Vol. xiv. p. 705.

Rothberger, J. (1900). Zeitschr. f. Hyg., Vol. xxxiv. p. 84.

SAVAge, W. G. (1905). Journ. of Hyg., Vol. v. p. 149.

Sмith, Тнeobald (1891). Centralbl. $f$. Bakt., x. p. 181.

$$
\text { (1895). } \quad-\quad \text { xviII. pp. 1, 494, } 589 .
$$

Strong, L, W. (1899). Centralbl. f. Bakt., I. xxv. p. 49.

Voges and Proskauer (1898). Zeitschr.f. Hyg., Vol. xxvitt. p. 20.

Weissenfeld (1900). Zeitschr. f. Hyg., xxxv. p. 78.

Winslow, C. E. A. (1902). Centralbl. f. Bakt., I. Ref. xxxi. p. 306. 